FUNDAÇÃO GETULIO VARGAS

ESCOLA DE ECONOMIA DE SÃO PAULO

RICARDO BUSCARIOLLI PEREIRA

WHAT IF FIRMS ADJUST THEIR DEBT-EQUITY RATIOS TOWARD A TARGET RANGE?

São Paulo

2009 
RICARDO BUSCARIOLLI PEREIRA

WHAT IF FIRMS ADJUST THEIR DEBT-EQUITY RATIOS TOWARD A TARGET RANGE?

Thesis presented in partial fulfillment of the requirements for the degree of Master in Economics at the São Paulo School of Economics, Fundação Getulio Vargas.

Knowledge Area: Corporate Finance

Advisor: Prof. Dr. Rodrigo De Losso da Silveira Bueno

São Paulo 
Pereira, Ricardo Buscariolli.

What if firms adjust their debt-equity ratios toward a target range? / Ricardo Buscariolli Pereira - 2009

$80 \mathrm{f}$.

Orientador: Rodrigo De Losso da Silveira Bueno.

Dissertação (mestrado) - Escola de Economia de São Paulo.

1. Estrutura de capital. 2. Alavancagem (Finanças). 3. Empresas - Finanças - Modelos matemáticos. 4. Análise econômico-financeira. I. Bueno, Rodrigo De Losso da Silveira. II. Dissertação (mestrado) - Escola de Economia de São Paulo. III. Título. 
RICARDO BUSCARIOLLI PEREIRA

\section{WHAT IF FIRMS ADJUST THEIR DEBT-EQUITY RATIOS TOWARD A TARGET RANGE?}

Thesis presented in partial fulfillment of the requirements for the degree of Master in Economics at the São Paulo School of Economics, Fundação Getulio Vargas.

Knowledge Area: Corporate Finance

\section{Data da aprovação}

$18 / 08 / 2009$

Thesis comitee:

Prof. Dr. Rodrigo De Losso da Silveira Bueno (Advisor) - FGV - EASP

Prof. Dr. Antonio Gledson de Carvalho FGV - EASP

Prof. Dr. Denisard Cneio de Oliveira Alves - FEA - USP 
To my granddad Luiz Buscariolli who taught me everything that really matters. 


\section{Acknowledgements}

It would have been impossible for me to finish anything without the help of many. First of all, my family, who have been supportive my whole life and are doubtless the main responsible for any achievement I may accomplish.

Natalia Dus Poiatti, not only for making this thesis possible but also for dealing with my whining personality.

All my colleagues and friends at Fundação Getulio Vargas: Maúna Baldini, Thaís Innocentini, Fulvia Hessel, Joelson Sampaio, and Rodrigo Tolentino. In particular, I'd like to thank Juliana Inhasz, Wagner Monteiro, Caio Mussolini, and Thiago Rodrigues for all the talk and support during these tough times.

My friends Humberto Cacioli, Jhonata Emerick, André Garcia, Wilson Grava, Rafael Madrona, Jander Minesso, Luiz Henrique Oriani, Vitor Puppin, and Thiago Zamorano.

My friends at Alianti: Rômulo Fainbaum, André Oda, Alexander Quinto, and Claudia Yoshinaga.

At last, but definitely not least, my advisor Rodrigo De Losso da Silveira Bueno for all the help, friendship, and all the lifts back to my city. 


\section{RESUMO}

Nós estimamos faixas-alvo ótimas de estrutura de capital controlando por uma série de características específicas de cada firma e levando em consideração a correlação serial proveniente do componente dinâmico da escolha do nível de alavancagem. Então nós examinamos empiricamente se as firmas ajustam dinamicamente em direção às faixas ótimas estimadas. Nossa análise sugere que o comportamento observado é consistente com a noção de ajustamento para faixas.

Palavras-chave: Estrutura de capital, Alavancagem, Probit Ordenado Dinâmico. 


\begin{abstract}
We estimate optimal target-ranges of capital structure controlling for a series of firmspecific characteristics and accounting for the serial correlation that arises from the dynamic component of the leverage choice. Then, we empirically examine if firms adjust their leverages toward the estimated optimal ranges. Our analysis suggests that the observed behavior of firms is consistent with the notion of range-adjustment.
\end{abstract}

JEL classification: G32

Key Words: Capital Structure, Leverage, Dynamic Ordered Probit. 


\section{List of Figures}

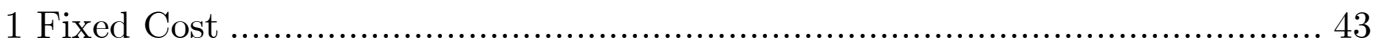

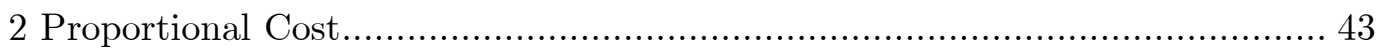

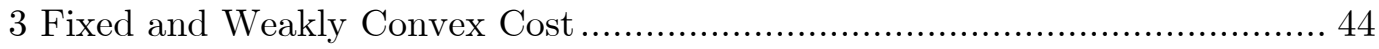

4 Distribution of the levels of leverage ........................................... 45 


\section{List of Tables}

1 Level of leverage

2 Descriptive statistics of ranges generated by breaking the level of leverage in intervals of the same width (ISW)

3 Descriptive statistics of ranges generated by breaking the level of leverage in intervals with the same number of firms (SNF)

4 Estimating ranges

5 Predicted probabilities

6 Directions of the partial effect

7 Marginal effects of a unit change in capital structure determinants when ranges are coded under the ISW criterion 53

8 Marginal effects of a one standard deviation change in capital structure determinants when ranges are coded under the ISW criterion

9 Marginal effects of a one unit change in capital structure determinants when ranges are coded under the SNF criterion .57

10 Marginal effects of a one standard deviation change in capital structure determinants when ranges are coded under the SNF criterion 59

11 Marginal effects of the lagged dependent variable indicator on the model of 5 categories when ranges are coded under the ISW criterion 61

12 Marginal effects of the lagged dependent variable indicator on the model of 10 categories when ranges are coded under the ISW criterion 62

13 Marginal effects of the lagged dependent variable indicator on the model of 15 categories when ranges are coded under the ISW criterion 
14 Marginal effects of the lagged dependent variable indicator on the model of 5 categories when ranges are coded under the SNF criterion....................64

15 Marginal effects of the lagged dependent variable indicator on the model of 10 categories when ranges are coded under the SNF criterion

16 Marginal effects of the lagged dependent variable indicator on the model of 15 categories when ranges are coded under the SNF criterion .66

17 In-sample and out-of-sample predictability 67

18 Inertia 68 


\section{Contents}

$\begin{array}{ll}1 \text { Introduction } & 01\end{array}$

2 Estimating ranges $\quad 05$

2.1 Dynamic Ordered Probit ....................................................... 06

2.1.1 Predicted Probabilities............................................ 10

2.1.2 Partial effects of continuous covariates ......................11

2.1.3 Partial effects of discrete covariates ......................... 12

2.2 Data .................................................................................... 13

2.3 Capital structure determinants ........................................ 14

2.4 Measure of leverage and definition of ranges ........................ 18

3. Empirical findings 21

3.1 Estimated coefficients................................................ 22

3.2 Predicted probability............................................... 24

3.3 Partial effects ...................................................................25

4 Testing the estimated models .......................................................27

4.1 In-sample and out-of-sample predictability .......................27

4.2 Inertia in and out of the optimal range ..............................29

6 Final Remarks

7 Appendix 32

7.1 Appendix A: Adjustment costs and target range ....................32

7.1 Appendix B: Likelihood function...................................... 35

7.2 Appendix C: Definition of variables ...................................37 
7.3 Appendix D: Intercept in ordered probt models...................38 


\section{Introduction}

Recent papers such as Graham and Harvey (2001), Leary and Roberts (2005) and Hovakimian and Li (2008) suggest that firms dynamically rebalance their capital structures toward a target range, composed by a set of equally admissible leverage levels, instead of a specific target point. If rebalancing toward a target range actually take place, empirical evidence drawn from tests that assume continuous adjustment aiming at target levels, such as inertia (Welch, 2004) and partial adjustment (Fama and French, 2002), may be compromised.

Since there is no empirical evidence confirming range-adjustment behavior there has been no attempt to estimate these ranges. Therefore, we do not know the significance and the partial effects of capital structure determinants (e.g., firm size, product uniqueness, etc.) under this range-adjustment framework. This is the first point of this paper; we start by estimating proxies for the optimal target ranges controlling for firm-specific characteristics in order to measure the significance, direction and size of each capital structure determinant. Then, we compare the observed readjustment behavior with the one expected in case firms are indeed adjusting toward ranges.

Since a priori we do not know anything about the characteristics of the optimal ranges, such as their widths or how they are chosen, we test different proxies. First, we use two criteria to define the range in which a firm is: (1) we code the market debt-equity ratios into categories, (2) we rank all the firms in each year according to their levels of leverage and build up groups with the same number of firms each. Then, we estimate a dynamic ordered probit model, accounting for the possibility of serial correlation in errors. We repeat this process for 3 range-widths and 3 group sizes.

Once we have estimates for the proxies of the optimal ranges, we test first the 
in-sample and out-of-sample predictability of the model and then we test the inertia hypothesis suggested by Welch (2004) for the adjustments made within and the ones outside the calculated optimal range. For two models we find that inertia is significantly stronger when the firm's leverage is within the optimal range, which we interpret as evidence supporting range-adjustment behavior.

From a more theoretical point of view, range-adjustment behavior makes sense if there is have evidence that:

1. Firms do have a target for their capital structures.

2. This target may not be a single value, but a set of values.

The debate about the first point, i.e., whether or not companies put effort into maintaining an optimal capital structure, is on since Modigliani and Miller's (1958) seminal paper. Some models imply that firms choose their optimal leverage levels by trading off costs and benefits of debt, therefore, there is a target that should be pursued (that is the case of dynamic tradeoff models such as Fischer, Heinknle and Zechner (1989)). In other models such as Myers (1984) and Myers and Majluf (1984), there is no room for an optimal debt-equity ratio.

The empirical evidence on targeting and dynamic rebalancing is mixed (ShyanSunders and Myers, 1999). Baker and Wurgler (2002) suggest that there is no active rebalancing toward a target at all. According to them, changes in capital structure result from the firm's attempts to time the market. Welch (2004) also reports evidence against dynamic rebalancing suggesting that firms are inactive on reacting to equity price shocks, what characterizes "inertia" behavior. The slow speed of adjustment of debt ratios towards their targets, reported by Fama and French (2002) and Kayhan and Titman (2007), is also considered to be an evidence of the inexistence of target leverage. 
Some authors, on the other hand, present evidence confirming dynamic rebalancing. Leary and Roberts (2005) reinterpret the evidences found by both Baker and Wurgler (2002) and Welch (2004) showing that, if the adjustment of capital structure is costly, the conclusions they drawn is inaccurate. They go further; continuous readjustment is not the optimal behavior according to the form of the cost function. Their analysis also suggests that partial adjustment models can return speeds of adjustment that are too slow simply because firms remain inactive until the benefits of the adjustment outweigh costs. Graham and Harvey (2001) also provide evidence in favor of rebalancing behavior. The authors ask financial decision makers (CFO's) if they have targets for their debt-equity ratios; $71 \%$ indicated having a target range and $10 \%$ stated to have a strict point to which they readjust. Graham and Harvey's (2001) paper is especially interesting because it deals not only with the existence of a target but also with the nature of this target.

Therefore, there is evidence that firms indeed have a target for their capital structures. This target is not directly observable and may not be a single point, however it is possible to proxy it using variables such as the firm's average debt ratio over the relevant sample period (Myers, 2001) or regressing the observed debtequity ratios on a set of capital structure determinants, usually chosen to proxy costs and benefits of debt and the impact of information asymmetry (Rajan and Zingales, 1995; Leary and Roberts, 2005; Flannery and Rangan, 2006; Lemmon, Roberts and Zender, 2006). For this reason, empirical papers usually refer to the predicted value of these regressions as "target capital structure" (or "optimal capital structure"). We can say, then, that any empirical research on the validity of target-adjustment behavior tests actually a joint hypothesis that the chosen proxy is close enough to the real target (Hovakimian and Li, 2008).

It is usually assumed that the target is a single value, what is at the heart of 
partial adjustment models, for instance. However, as Graham and Harvey (2001) report, this may not be the case. Leary and Roberts (2005) show that, assuming that rebalancing is costly, the optimizer firm will not rebalance toward a specific point unless the readjustment costs are fixed. In order to show that they simulate the behavior an optimizing agent presents when readjustment costs are (1) fixed, (2) proportional, and (3) fixed plus weakly convex. Figures 1, 2, and 3 (which correspond to Figure 1 of Leary and Roberts (2005)) illustrate the behavior for each of these cost structures (we provide more details about Leary and Roberts (2005) in Appendix A).

$$
\begin{aligned}
& {[\text { - insert Figure } 1 \text { here - ] }} \\
& {[\text { - insert Figure } 2 \text { here - ] }} \\
& {[\text { - insert Figure } 3 \text { here - ] }}
\end{aligned}
$$

The form of the readjustment costs is therefore crucial to understand which path we expect firms to follow. Leary and Roberts (2005) shed light on that matter too; using a duration analysis they provide evidence that the adjustment costs are fixed and weakly convex. Therefore, we expect that firms will present a behavior similar to the one illustrated in that Figure 3, i.e., they adjust toward a range.

Although we have arguments consistent with the notion that firms do have a target and, furthermore, that this target may be composed by a set of debt-equity ratios, there is no empirical paper providing evidence confirming such prior or dealing with the consequences of this kind of readjustment behavior. This is where our main contribution lies; by modeling the optimal ranges we are able not only to measure the directions and the significance of the capital structure determinants we take into account but also to draw empirical evidence on the validity of range-adjustment behavior. 
The remainder of the paper is organized as follows. Section 2 describes the approach we use to estimate the target ranges, the dataset, the independent and dependent variables we use. Section 3 presents the results of the estimation of the target ranges. In Section 4 we perform in-sample and out-of-sample tests and we estimate the inertia behavior within and outside of each estimated range in order to compare the models presented in Section 3. Section 5 concludes the paper.

\section{Estimating ranges}

Our interest lies in estimating the range in which a firm is more likely to be, which we loosely refer to as target (or optimal) range, controlling for a vector of firm-specific characteristics. The ranges we are modeling have ordinal meaning - the first range has the observations with the lowest levels of leverage, the last range is the one with the highest levels.

Thus, even though the level of leverage has quantitative meaning we wish to acknowledge the discrete and ordered nature of the response (Wooldridge, 2001). We face then what is known as "ordinal response", which combined with the assumption that errors are normally distributed makes it natural to choose the ordered probit model.

We assume that the choice of the ranges depends on the same firm-specific characteristics that are considered to influence the choice of leverage levels. We also take into account that this process can be serially correlated. Lemmon, Roberts and Zender (2006) report that coefficients of capital structure determinants decrease about $65 \%$ in the market leverage regression after accounting for firm fixed effects and serially correlated errors, what they attribute to a possible consequence of costly financial adjustments. They add that parameter estimates that do not consider firm 
specific effects and serial correlation can be said to be "suspect". In this spirit, we add a one-period lagged dependent variable ${ }^{1}$ to deal with this issue. The estimation of ordered probit models with a lagged dependent variable and unobserved heterogeneity is not straightforward; we follow Wooldridge (2005) in this task.

Section 2.1 presents the estimations strategy. Section 2.1.1, 2.1.2, and 2.1.3 show the process of finding predicted probabilities, partial effects of continuous, and discrete variables, respectively. Section 2.2 describes the data and Section 2.3 shows the capital structure determinants. Section 2.4 explains how we code the categories representing the ranges that are the dependent variables in the model.

\subsection{Dynamic Ordered Probit}

Let $y_{i t}$ be an ordered response of firm $i$ in period $t$ representing the group or the categories in which we divide the debt-equity ratios. $y_{i t}$ take on the values $\{1,2, \ldots, J\}$ for some $J \in \mathbb{Z}$. We define an abstract construct called underlying latent variable, $y_{i t}^{*}$, which is determined as follows

$$
y_{i t}^{*}=\mathbf{z}_{i t}^{\prime} \gamma+r_{i, t-1}^{\prime} \rho+c_{i}+e_{i t}
$$

Where $e_{i t}$ has a standard conditional normal distribution, $\mathbf{z}_{i t}$ is the $K X 1$ vector of covariates (in our case, capital structure determinants at time $t$, which we describe in Section 3.3), $c_{i}$ is the unobserved heterogeneity and $r_{i, t-1}$ is the $J X 1$ vector of $J$ indicators $1\left[y_{i, t-1}=j\right], j=1, \ldots, J$. We do not observe the latent variable, instead we observe $y_{i t}$, which is determined by $y_{i t}^{*}$ being within a particular interval limited by cut points (that must also be estimated). Let $\mu_{1}<\mu_{2}<\cdots<\mu_{J}$ be these

\footnotetext{
${ }^{1}$ We choose to add just a one-period lagged dependent variable to avoid data-related complications we explain in Section 2.1; nothing is wrong in adding more lags, though.
} 
unknown cut points (or threshold parameters), then we have

$$
\begin{aligned}
& y_{i t}=0 \quad \text { if } \quad y_{i t}^{*} \leq \mu_{1} \\
& y_{i t}=1 \quad \text { if } \quad \mu_{1} \leq y_{i t}^{*} \leq \mu_{2} \\
& \vdots \\
& y_{i t}=J \quad \text { if } \quad y_{i t}^{*}>\mu_{J-1}
\end{aligned}
$$

For $J$ categories there are $J-1$ cut points to be estimated. There are two important features of dynamic ordered probit for panel data; first, the unobserved heterogeneity cannot be eliminated in the same way they are in linear models with additive unobserved effect (by taking the first difference, for instance). Second, the distribution of $y_{i t}$ depends on its initial value $y_{i 0}$, in our case the indicator variable $r_{i, 0}$, which is tracked back by the $r_{i, t-1}$ added in the underlying latent variable $y_{i t}^{*}$. Wooldridge (2005) suggests a way of dealing with both of these issues by modeling the distribution of the unobserved effect conditional on the initial value and all exogenous explanatory variables. He assumes that the unobserved heterogeneity can be modeled as:

$$
c_{i} \mid y_{i 0}, \mathbf{z}_{i} \sim \operatorname{Normal}\left(\alpha_{0}+y_{i 0}^{\prime} \alpha_{1}+\mathbf{z}_{i}^{\prime} \alpha_{2}, \sigma_{a}^{2}\right)
$$

In which, $y_{i 0}$, in an abuse of notation, is the variable that represents a full set of indicators $1\left[r_{i, 0}=j\right], j=1, \ldots, J$, which describes all of the possible states of the initial outcome. $\mathbf{z}_{i}$ is the vector of all nonredundant capital structure determinants in all time periods (so, firm $i$ in period $t$ has among its covariates all of its capital structure determinants in every period considered). Following this approach we can write $c_{i}$ as 


$$
c_{i}=\alpha_{0}+y_{i 0}^{\prime} \alpha_{1}+\mathbf{z}_{i}^{\prime} \alpha_{2}+a_{i}
$$

Where $a_{i}$ is independent of $\left(y_{i 0}, \mathbf{z}_{i}\right)$ and is distributed as Normal $\left(0, \sigma_{a}^{2}\right)$. If we plug equation (4) to (1) we find

$$
y_{i t}^{*}=\mathbf{z}_{i t}^{\prime} \gamma+r_{i, t-1}^{\prime} \rho+\alpha_{0}+y_{i 0}^{\prime} \alpha_{1}+\mathbf{z}_{i}^{\prime} \alpha_{2}+a_{i}+e_{i t}
$$

Which can be written as

$$
y_{i t}^{*}=\mathbf{x}_{i t} \beta+\varepsilon_{i t}
$$

In which

$$
\begin{aligned}
\mathbf{x}_{i t} & =\left(1, \mathbf{z}_{i t}^{\prime}, r_{i, t-1}^{\prime}, y_{i 0}^{\prime}, \mathbf{z}_{i}^{\prime}\right) \\
\varepsilon_{i t} & =a_{i}+e_{i t}
\end{aligned}
$$

Where $\beta$ is the vector of parameters to be estimated. There is nothing wrong with adding more lags to the structural model but instead of using just $y_{i 0}$ we would have to add $y_{i,-1}$ as well, what increases data requirements.

$y_{i t}^{*}$ is not observable, thus, we must estimate both parameters and cut points using $y_{i t}$ as the dependent variable. Now, under this new formulation of the latent variable, we can deal with the initial value problem and with the unobserved heterogeneity as if we were working with an ordinary random effects ordered probit (since we assume that $e_{i t}$ and $a_{i}$ have standard conditional normal distributions and $a_{i}$ is independent of $\left.\left(y_{i 0}, \mathbf{z}_{i}\right)\right)$. We just have to add the set of indicators $y_{i 0}$ and $\mathbf{z}_{i}$. The later vector is supposed to contain all the covariates for all the periods, but again we follow 
Wooldridge (2005) who suggests us to use the time average $\overline{\mathbf{z}}_{i}$ of each covariate to conserve on degrees of freedom.

Intuitively, to find the likelihood function we have to derive the conditional distribution of $y_{i t}$ given $\mathbf{x}_{i t}$ computing each response probability

$$
\begin{aligned}
P\left(y_{i t}\right. & \left.=1 \mid \mathbf{x}_{i t}\right)=P\left(y_{i t}^{*} \leq \mu_{1} \mid \mathbf{x}_{i t}\right)= \\
& =P\left(\mathbf{x}_{i t} \beta+\varepsilon_{i t} \leq \mu_{1} \mid \mathbf{x}_{i t}\right)=\Phi\left(\mu_{1}-\mathbf{x}_{i t} \beta\right) \\
P\left(y_{i t}\right. & \left.=2 \mid \mathbf{x}_{i t}\right)=P\left(\mu_{1}<y_{i t}^{*} \leq \mu_{2} \mid \mathbf{x}_{i t}\right)=\Phi\left(\mu_{2}-\mathbf{x}_{i t} \beta\right)-\Phi\left(\mu_{1}-\mathbf{x}_{i t} \beta\right) \\
& \vdots
\end{aligned}
$$

Where $\Phi$ represents the c.d.f. of the normal distribution function what leads to a $\log$-likelihood function for firm $i$ in period $t$ with the following structure

$$
\begin{aligned}
& l_{i t}(\mu, \beta)=1\left[y_{i t}=1\right] \ln \left[\Phi\left(\mu_{1}-\mathbf{x}_{i t} \beta\right)\right]+1\left[y_{i t}=2\right] \ln \left[\Phi\left(\mu_{2}-\mathbf{x}_{i t} \beta\right)\right. \\
& \left.-\Phi\left(\mu_{1}-\mathbf{x}_{i t} \beta\right)\right]+\cdots+1\left[y_{i t}=J\right] \ln \left[1-\Phi\left(\mu_{J-1}-\mathbf{x}_{i t} \beta\right)\right]
\end{aligned}
$$

which can be generalized to $T$ time periods to yield the desired final log-likelihood function (we write down the full likelihood function in Appendix B).

This approach has some criticism related to the assumption made about $c_{i}$, i.e., equation (3) All the eventual drawbacks of the approach are stronger if we work with unbalanced panel dataset because we will have to specify a conditional distribution of $c_{i}$ for each configuration of missing data (Wooldridge, 2005). For this reason, we work with balanced panel data in this paper.

Finally, this way of estimating ordered probit assumes that the model must have an intercept $\left(\alpha_{0}\right)$, represented by the number 1 in the vector $\mathbf{x}_{i t}$. But in ordered 
probit models the intercept is implicit in the cut points and it is therefore indirectly included in the model (see Appendix D for more details).

The parameters we estimate using the rationale described in this subsection do not correspond to the partial effects of the covariates. In order to find them we have to perform some calculation we describe in the following subsections.

\subsubsection{Predicted Probabilities}

The first thing we want to find when we estimate an ordered probit model are the predicted probabilities, i.e., the probabilities for the average firm of belonging to each of the categories. We choose the "calculation from individuals" 2 procedure in order to find these probabilities, which consists of first finding the probability of each individual firm of being in each one of the categories that were considered and then averaging those values. For instance, consider the case of 5 categories, once we have estimated the vector $\beta$ and the cut points, the probability for firm $i$ of being within each one of them is

$$
\begin{aligned}
& P\left(y_{i t}=1 \mid \mathbf{x}_{i t}\right)=P\left(y_{i t}^{*} \leq \mu_{1} \mid \mathbf{x}_{i t}\right)=\Phi\left(\mu_{1}-\mathbf{x}_{i t} \beta\right) \\
& P\left(y_{i t}=2 \mid \mathbf{x}_{i t}\right)=\Phi\left(\mu_{2}-\mathbf{x}_{i t} \beta\right)-\Phi\left(\mu_{1}-\mathbf{x}_{i t} \beta\right) \\
& P\left(y_{i t}=3 \mid \mathbf{x}_{i t}\right)=\Phi\left(\mu_{3}-\mathbf{x}_{i t} \beta\right)-\Phi\left(\mu_{2}-\mathbf{x}_{i t} \beta\right) \\
& P\left(y_{i t}=4 \mid \mathbf{x}_{i t}\right)=\Phi\left(\mu_{4}-\mathbf{x}_{i t} \beta\right)-\Phi\left(\mu_{3}-\mathbf{x}_{i t} \beta\right) \\
& P\left(y_{i t}=5 \mid \mathbf{x}_{i t}\right)=1-\Phi\left(\mu_{4}-\mathbf{x}_{i t} \beta\right)
\end{aligned}
$$

In this way, the "optimal" category predicted for firm $i$ is simply the outcome

\footnotetext{
${ }^{2}$ The alternative to this procedure is the "calculation at the mean" in which we use the averages of all the covariates to determine the average firm. Unless the sample size is very small or the data are highly skewed and affected by outliers both of procedures will give a very similar result (Greene and Hensher, 2008).
} 
with the highest probability. When we average these probabilities across all the individuals and all time periods we find the predicted probabilities for each range.

\subsubsection{Partial effects of continuous covariates}

The parameter vector $\beta$ estimated by ordered probit is of limited interest for it is not equal to the vector of marginal effects of the regressors. We are interested in the effects of each covariate in response probabilities $P\left(y_{i t}=J \mid \mathbf{x}_{i t}\right)$ when these covariates change in one unit. Consider the case with 5 categories, the marginal effect of the independent variable $x_{k}$ for firm $i$ in time $t$ is

$$
\begin{aligned}
& \frac{\partial P\left(y_{i t}=1 \mid \boldsymbol{x}_{i t}\right)}{\partial x_{k}}=-\beta_{k} \phi\left(\mu_{1}-\mathbf{x}_{i t} \beta\right) \\
& \frac{\partial P\left(y_{i t}=2 \mid \boldsymbol{x}_{i t}\right)}{\partial x_{k}}=\beta_{k}\left[\phi\left(\mu_{1}-\mathbf{x}_{i t} \beta\right)-\phi\left(\mu_{2}-\mathbf{x}_{i t} \beta\right)\right] \\
& \frac{\partial P\left(y_{i t}=3 \mid \boldsymbol{x}_{i t}\right)}{\partial x_{k}}=\beta_{k}\left[\phi\left(\mu_{2}-\mathbf{x}_{i t} \beta\right)-\phi\left(\mu_{3}-\mathbf{x}_{i t} \beta\right)\right] \\
& \frac{\partial P\left(y_{i t}=4 \mid \boldsymbol{x}_{i t}\right)}{\partial x_{k}}=\beta_{k}\left[\phi\left(\mu_{3}-\mathbf{x}_{i t} \beta\right)-\phi\left(\mu_{4}-\mathbf{x}_{i t} \beta\right)\right] \\
& \frac{\partial P\left(y_{i t}=5 \mid \boldsymbol{x}_{i t}\right)}{\partial x_{k}}=\beta_{k}\left[\phi\left(\mu_{4}-\mathbf{x}_{i t} \beta\right)\right]
\end{aligned}
$$

Where $\phi$ represents the p.d.f. of the normal distribution function, i.e., the first derivative of $\Phi\left(\Phi^{\prime}\right)$.

We see that the marginal effect of $x_{k}$ have the opposite sign of the estimated $\beta_{k}$ for the first category and the same sign for the last. The intermediate effects, however, are ambiguous and will depend on the probability densities. Once we find the marginal effect for each firm in each point in time one can just average those values within each range to find the Average Partial Effects (APE). If we want to know the APE of covariate $x_{k}$ in category $y_{i t}=3$ when there are 5 categories, for 
instance, we calculate

$$
A P E_{3}\left(x_{k}\right)=\frac{1}{T} \frac{1}{N} \sum_{t=1}^{T} \sum_{i=1}^{N}\left[\phi\left(\mu_{2}-\mathbf{x}_{i t} \beta\right)-\phi\left(\mu_{3}-\mathbf{x}_{i t} \beta\right)\right] \beta_{k}
$$

The APE's show the expected change in probability per unit change in the covariate. Sometimes a one unity change is too much (or too little) depending on the mean and the standard deviation of the variable being evaluated. To be more informative it is also convenient to express the marginal effect in terms of standard deviation. The APE in standard deviation terms for covariate $x_{k}$ in category 3 , for instance is

$$
A P E_{S D, 3}\left(x_{k}\right)=A P E_{3}\left(x_{k}\right) \times \sigma_{k}
$$

In which $\sigma_{k}$ is the standard deviation of covariate $x_{k}$. In order to be as informative as possible, we report both the partial effects in terms of a unit change in convariates and a unit change in standard deviation.

\subsubsection{Partial effects of discrete covariates}

To calculate the partial effects of discrete variables we have to compare the probabilities we calculate when the dummy variable takes value 0 and when it takes value 1 , while holding all the others at their sample means. The partial effect of the dummy variable $x_{k}$ for firm $i$ can be calculated in the following way (here we omit the time subscript)

$$
P E_{i, s}\left(x_{k}\right)=P\left(y_{i}=s \mid x_{k}=1\right)-P\left(y_{i}=s \mid x_{k}=0\right)
$$

For the case of 5 categories, for instance, $s$ ranges from 1 to 5 . We assume, by doing this procedure, that the difference in probabilities is all due to the effect of the dummy variable, therefore that is the partial effect of the dummy variable. We then 
take the time average of the partial effects of each range in order to get the APE of the discrete variables.

\subsection{Data}

Our data is taken from COMPUSTAT for the period 1990-2006. We exclude regulated (SICs 4900-4999) and financial firms (SICs 6000-6999) for which capital structure decisions are considered to be governed by special factors (Flannery and Rangan, 2006) and also to be consistent with other studies (Frank and Goyal (2003), Leary and Roberts (2005), Lemmon, Roberts and Zender (2006)). We exclude observations with missing data for both book value of assets and any of the components of the debt-equity ratio (total debt and market value of equity).

For the reasons stated in Section 3.1 we need all observations in our sample to start and finish at the same date. We have data available until 2006, set as ending date, and 1990 is the starting date. By doing that we end up with 19,168 firm years observations (the highest value possible in our sample) ${ }^{3}$ : 1,198 firms, each with a time series of 16 years of observations. We discard observations from the first year (1990) in order to have no missing values for the lagged dependent variable.

Some studies exclude small firms stating that, for them, the adjustment costs may be unusually large; others limit the size of market to book ratio (Baker and Wurgler (2002); Leary and Roberts, 2005), among other trimmings. We include all firms in our estimation and we do not trim the upper and the lower percentiles. We do so because the exclusion of extreme observations would have to be followed by the exclusion of the observations of the entire firm in order to remain with a balanced

\footnotetext{
${ }^{3}$ If our start date was 1980, for instance, we would have 15,860 firm-year observations, this number keeps rising until 1990 from which it starts to decline
} 
panel, what would diminish too much the sample ${ }^{4}$.

\subsection{Capital structure determinants}

As is usually done in the empirical capital structure literature, we assume that firms choose their debt-equity ratios by balancing the possible costs and benefits of debt. These costs and benefits (that are supposed to vary according to firm's characteristics and change over time) and the way they are correlated with leverage are described by different theoretical approaches. The static tradeoff theory associates the costs of debt with bankruptcy costs (administrative costs and loss of reputation) and the benefits of debt with tax shield. The pecking order theory predicts that firms will prefer internal funds rather than external to finance themselves and when they do need to get external funding they will prefer to do so by issuing debt instead of equity. According to agency based models, the costs of debt are related to asset substitution and underinvestment and the benefits of debt are associated with the prevention of managerial discretion and reduction of the free cash flow problem (Harris and Raviv, 1991).

These costs and benefits are tested in empirical papers through proxies we call "capital structure determinants", which are firm-specific characteristics that change over time. We follow Rajan and Zingales (1995), Fama and French (2002), Leary and Roberts (2005), among others, in the process of choosing the set of determinants, attempting to be as comprehensive as possible. We describe our independent variables (they are also defined in Appendix B in terms of their COMPUSTAT items) and how they are supposed to be correlated with leverage according to the theories

\footnotetext{
${ }^{4}$ If we trim the lowest and the highest percentile of each covariate, as Leary and Roberts (2005) do, when we balance the dataset our sample falls to 459 firms.
} 
mentioned earlier (Table 6 summarizes the direction of the effects according to the different theories):

- Firm size (firm sales in period $t$ divided by total sales in sample in period $t$ ): The effect of size is ambiguous (Rajan and Zingales, 1995). If we consider that large firms are less likely to go bankrupt it is supposed to have a positive impact on debt issuance, i.e., the leverage will be higher in larger firms. On the other hand, a larger size signs good things for outside investors, as a consequence a large firm may prefer to issue equity, lowering the leverage.

- Volatility of cash flow (change in net income normalized by book assets): This measure is potentially positively correlated with a firm's probability of financial distress (Minton and Schrand, 1999) and for that reason it is supposed to be negatively correlated with leverage.

- Product uniqueness (ratio of selling expenses to total sales): The logic behind this measure is that customers are supposed to be reluctant to buy highly differentiated products from a company because they fear being left without aftersales service, spare parts or product upgrades in case the firm goes bankrupt (Opler and Titman, 1994). The same rationale applies if we consider that the cost of switching to another vendor's product may be substantial if products are highly differentiated (Arping and Loranth, 2006). Opler and Titman (1994) actually find that high leveraged firms tend to loose market share to their less leveraged competitors. This measure is, therefore, supposed to be negatively correlated with leverage.

- Asset tangibility (assets attributable to property, plant and equipment divided by total assets): Tangible assets serve as collateral and have more value in case 
of liquidation. For these reasons lenders are supposed to be more willing to supply loans what increases leverage.

- Depreciation and amortization (depreciation and amortization divided by total assets): This ratio is a measure of nondebt tax shield that offset the tax benefit of debt financing (Leary and Roberts, 2005). It is thought to be positively correlated with leverage.

- Growth and investment opportunities (capital expenditure divided by total assets): Under models based on agency costs it is expected a negative correlation with leverage. According to Harris and Raviv (1991) if the opportunities of asset substitution are more limited then the levels of debt will be higher. Hence, if a firm has small opportunities of growth it will be more highly levered. Rajan and Zingales (1995) also suggest that more equity financing will be used in case growth and investments opportunities are high because high levered firms are more likely to pass up profitable investment opportunities.

- Market-to-book ratio (total assets minus book equity plus market equity all divided by total assets): It is also considered a measure of investment opportunity and has a negative correlation with leverage. This ratio may also reflect the effect of stock prices. If a firm issues stocks when their price is high relative to the book value we may verify a negative correlation between market-to-book ratio and leverage (Rajan and Zingales, 1995).

- Profitability (after-tax operating income divided by total assets): The expected effect of this measure is ambiguous. The pecking order theory predicts that more profitable firms will prefer finance with internal funds instead of debt therefore lowering the leverage. Under agency-based models, if the market for 
corporate control is effective it will force firms to commit to pay out cash, thus firms will increase their leverages.

- Internal reserves (cash and marketable securities divided by total assets): The pecking order theory predicts that firms will use less external financing when their internal reserves are higher, so the correlation with leverage is negative.

- Altman's Z-score (3.3 times earnings before interest and taxes plus sales plus 1.4 times retained earnings plus 1.2 times working capital): This is a version of Altman's Z-score suggested by Leary and Roberts (2005). This measure is supposed to indicate the financial health of a firm and predicts the probability of bankruptcy, the higher the Z-score the less likely it is for a firm to go bankrupt. We use this variable as a proxy for the costs of financial distress, according to tradeoff theory the higher the costs the lower the leverage. therefor it is supposed to be positively correlated with leverage.

In our estimation we use a one-period future value of capital expenditure to compute the "growth and investment opportunities measure" assuming that firms can anticipate their financial needs in one year. All the other capital structure determinants are lagged in one period. We do that because we want to work only with information that is known at the time the firm decides its capital structure. Apart from these variables we also add a dummy variable for each major industry group according to their SIC codes to control for any industry-specific effect ${ }^{5}$.

\footnotetext{
${ }^{5}$ We choose major industry groups instead of adding a dummy for each two-digit SIC code to save degrees of freedom. There are 10 of these groups summarizing SIC codes ranging from 01 to 89 (there is also the category 99, the SIC code for Nonclassifiable Establishments, which is ommited due to multicollinearity).
} 


\subsection{Measure of leverage and definition of ranges}

The dependent variable indicating the ranges we are interested in is discrete. Usually, in ordered choice models the variable is discrete by nature (such as bond rating or level of happiness, for instance) but in this paper we depart from a continuous measure of leverage which we code into categories ${ }^{6}$. Hence, our dependent variable depends in the first place on the way we measure de level of leverage (see Rajan and Zingales (1995)). Here we consider that the leverage of firm $i$ in period $t$ is measured by the market debt-equity ratio

$$
L_{i t}=\frac{D_{i t}}{D_{i t}+E_{i t}}
$$

where $D_{i t}$ is firm $i$ 's total debt in period $t$ and $E_{i t}$ is the market value of equity of firm $i$. The market debt-equity ratio is a continuos variable ranging from 0 to $1 ; 0$ represents the case in which the firm decides to totally finance itself with equity and 1 when it decides to issue only debt. Table 1 presents summary information of $L_{i t}$ and Figure 4 presents the histogram of all firm-year observations in the sample. Most of the companies have low leverages, as one sees in Figure 4 the distribution of leverage is strongly asymmetric. This means that the debt they issue to finance themselves is relatively moderate, which is represented by the average market debt-equity ratio of 0.21 .

\footnotetext{
${ }^{6}$ Note that we do have some sort of interval-coded data, what may suggest that we should be estimating an interval regression, which we are not. When interval regression is used the interest lies in the linear model (i.e., we would like to have the continuous variable but we just have the intervals) and the parameters estimated can be interpreted as if we had run an OLS. But in this paper we want the opposite; in every period we observe, for every firm in the sample, an interior point of the ranges and we want to find the probability of each firm to be within one of these ranges according to their characteristics.
} 


$$
\begin{aligned}
& \text { [ - insert Figure } 4 \text { here - ] } \\
& \text { [ - insert Table } 1 \text { here - ] }
\end{aligned}
$$

Once we find a measure for leverage, the second important issue is how to transform it into categories. This topic is a classic issue in text books of statistics. According to those books the choice of intervals always has some degree of arbitrariness, however they suggest an heuristic rule to help us to carry out this process. They say there should be from 5 to 15 intervals, with less than 5 too much information would be lost and more than 15 may compromise the objectives of grouping information. We use two different criteria to group firms into 5, 10 and 15, the first one (or the first range) always represent the one with the lowest levels of leverage and the last one represents the highest leverages:

1. Dividing leverage into Intervals of the Same Width (ISW): In this procedure we simply divide the possible leverages into ranges of the same width. For instance, for 5 categories the width of each range is $0.2\left(\frac{1}{5}\right)$, thus every firm with $L_{i t}$ higher than 0 and lower than 0.2 are grouped in Range 1 , firms with $L_{i t}$ higher than 0.2 and lower than 0.4 will be in Range 2. For 10 and 15 categories we do the same but categories are narrower, their width is $0.1\left(\frac{1}{10}\right)$ and $0.07\left(\frac{1}{15}\right)$ debtequity ratio units, respectively. Under the ISW procedure the lowest ranges indicate that firms choose low levels of debt to finance themselves, high ranges indicate a choice for higher debt, therefore the outcome is easy to interpret. The disadvantage is that we have to impose the widths of the ranges, what may be restricting too much the analysis.

2. Groups with the Same Number of Firms (SNF): Here we rank firms according to their leverages and create groups with the same number of firms per year. 
The first issue is how to rank all the firms in the sample, which is not so simple due to the ties in ranking that may eventually happen and also because of the asymmetric treatment of tails. The first thing we do is to associate to each observation a plotting position of the family

$$
\frac{i-a}{n-2 a+1}
$$

where $n$ is the number of firms. The value of $a$ is supposed to be chosen according to the interest of the researcher, we follow Weibull and Gumbel (Harter, 1984) who suggest that $a$ should be 0 . This yields the value 0.5 for the single middle value (when sample size is odd) and treats the tails symmetrically. We calculate this plotting position every year in our sample and then we group firms. For 5 categories, for instance, we group all the companies with the plotting position value between 0 and 0.2 (as we did in the first criterion described but instead of breaking the debt-equity ratios we use the plotting position variable) in year $t$. Under this procedure we do not have to impose the width of the range; in each year firms choose their levels of debt and we observe in which quantile of the distribution of debt-equity ratios a firm is. This approach makes sense if we assume that firms look at the market to compare themselves in order to choose their desired level of debt every year.

The categories we build have different features according to the way we break data. The ranges created using ISW have different numbers of firms, as we see in Table 2, most of them located in the first ranges, i.e. the ones with lower leverages. More than half of firm-year observations have leverages levels below 0.2. The average leverages within the first range are $0.07,0.03$ and 0.02 for division into 5, 10 and 15 categories respectively. Ranges with the highest leverages have just a few 
observations, 409 for 5 categories (mean average of 0.89), 165 for 10 categories (mean average of 0.94 ) and 100 for 15 categories (mean average of 0.96). This emulates the asymmetry seen in the distribution of leverage illustrated in Figure 4.

[ - insert Table 2 here - ]

Turning to the SNF way of breaking data; we are supposed to have ranges with the same number of firms, however, this number is not exactly the same due to ties in ranking (if two firms have the same plotting position value they will be in the same group), what can be seen in Table 3, where we can also note that the standard deviation is larger in ranges with higher leverages than the ones in which data is broken using ISW. That happens because there are more firms with low levels of leverage, therefore a group with the same number of firms and high leverage is more heterogenous in terms of levels of leverage.

[ - insert Table 3 here - ]

\section{Empirical findings}

To ease the presentation we discuss the estimates of the dynamic ordered probit described by equations 6 and 2 in three parts. First, we present the predicted coefficients and their levels of significance in section 3.1. We deal with the predicted averages and the partial effects of their covariates in sections 3.2, 3.3. Although we have to add many covariates to prevent omitted variable bias, as discussed in section 2, we only report coefficients and partial effects of the capital structure determinants, cut parameters, and the indicator of lagged dependent variables. The other added variables can be considered auxiliary to some extent and to avoid confusion their coefficients are not reported. The indicator of lagged dependent variables was included 
for all of the possible ranges in the model, that means that there were 5, 10 and 15 dummy variables for the models of 5, 10 and 15 categories, respectively. However, due to multicollinearity, one of these variables is always dropped within each model.

\subsection{Estimated coefficients}

Table 4 presents the results from the estimation of equations 6 and 2. There are three models for each grouping strategy (ISW or SNF) according to the number of categories in which data is broken $(5,10$, and 15$)$, therefore six models are reported in this paper.

[ - insert Table 4 here - ]

All of the six models we estimate are significant, what is indicated by the calculated LR statistics. The null hypothesis, which states that the model does not have explanatory power higher than the model with the intercept as the only independent variable, is always rejected. As a measure of the goodness-of-fit we calculate McFadden's Adjusted Pseudo R-squared ${ }^{7}$; we know that the closer it is to 1 the better

\footnotetext{
${ }^{7}$ McFadden's adjusted $\mathrm{R}$ squared is defined as $R_{A d j}^{2}=1-\frac{\ln \widehat{L}\left(\text { Model }_{F u l l}\right)-K}{\ln \widehat{L}\left(\text { Model }_{\text {Intercept }}\right)}$. Where $\widehat{L}$ is the estimated likelihood, $K$ is the number of coefficient estimated, Model $_{F u l l}$ is the model with predictors and Model $_{\text {Intercept }}$ is the model without predictors. The log likelihood of the intercept model corresponds to the total sum of squares, and the log likelihood of the full model is related to the sum of squared errors. The ratio of the likelihoods suggests the level of improvement over the intercept model offered by the full model. Subtracting $K$ is a means of penalizing a model for including too many predictors. If the predictors in the model are effective, then the penalty will be small relative to the added information of the predictors. However, if a model contains predictors that do not add sufficiently to the model, then the penalty becomes noticeable and the adjusted R-squared will decrease.
} 
the fitness of the model is, although this measure does not have a natural interpretation. The Pseudo R-squared only has meaning when compared to another pseudo R-squared of the same type, on the same data, predicting the same outcome. Hence, it is hard to make statements about which amount of ranges is better by using this measure but we can make comparisons between the ISW and the SNF criteria. As one sees in Table 4, the R-squareds for the SNF criterion are always slightly smaller than the ones we find by using the ISW criterion. The McFadden's Adjusted Pseudo R-squareds for the ISW (SNF) criterion are $0.22(0.21), 0.18(0.17)$, and $0.16(0.14)$ for the models with 5, 10, and 15 categories respectively. This difference between ISW and SNF is quite small, so according to this measure both criteria have quite similar goodness-of-fit.

Turning to capital structure determinants, Asset Tangibility, Depreciation and Amortization, Growth and Investment Opportunities are significant at one percent test level for all of the models we estimate. The determinant Internal Reserves is significant at one percent level for all of the models but the one with 10 ranges under the SNF criterion, in which it is significant at a five percent level Under the ISW criterion the determinant Volatility of Cash Flow is significant at one percent for 5 ranges (and is not significant in all the other models). Profitability is ten percent significant for both the model with 10 ranges under ISW and the one with 5 ranges under SNF. Almost all the indicators of lagged dependent variables (with just one exception) are significant at one percent level for all six models, what echoes the importance of considering serial correlation. All of the coefficients have similar values for all of the six models, what indicates a good robustness to the estimation. The main differences in the magnitude of the coefficients are in the estimated cuts, what is reflected in both the calculated predicted probability of each outcome and the partial effects of each covariate. 


\subsection{Predicted probability}

Table 5 shows the predicted probabilities, i.e., the probability for an average firm of being in each of the ranges we take into account, for the six models estimated. For the ISW criterion the probability of an average firm to be in range 1 is of $58 \%, 38 \%$ and $31 \%$ for division in 5, 10 and 15 categories respectively. These are the highest ones in each of the three models what reflects the low leverages in our sample and the unequal number of firm-year observations within each range. Note that the probabilities sum to 1 , as we would expect, and also that if we sum the probabilities for the first and the second ranges for the model with 10 categories we get the average probability of this firm of being in the first range for the case of 5 categories (the sum of probabilities of being in ranges 3 and 4 of the model with 10 categories gives the same probability of being in the second category of the model divided in 5 , and so forth). That happens because for 10 categories the width of ranges is 0.1 units of market debt-equity ratio and for 5 ranges the width is 0.2 what is consistent with the model we estimate (even though the estimated cut points are different for each model).

$$
\text { [ - insert Table } 5 \text { here - ] }
$$

Under the SNF way of breaking data one sees that the average firm will be somewhere close to a range in the middle since the number of firms is the same within each range per year. The probabilities for the average firm of being in each of the ranges is pretty similar but the highest ones are in Ranges $3(22 \%), 5(11 \%)$ and $7(7 \%)$ for the models with 5,10 and 15 categories. 


\subsection{Partial effects}

The economic significance and the direction of the calculated partial effects are shown in Tables 6 to 16, where we present the partial effects of the capital structure determinants for a unit and a standard deviation change in the covariates, and the partial effects of the indicator of the lagged dependent variables. In these tables we normalize values to range from 0 to 100 to facilitate the interpretation.

The directions of the partial effects of each model are summarized in Table 6 . Among the 1\% significant covariates the determinants Asset Tangibility and Depreciation and Amortization are negatively related to leverage, which is not in accordance to the predicted direction of these variables. All the others confirm the predicted directions. Among the covariates that are not one percent significant we can highlight the variables Firm Size, which is positively related to leverage, what reinforces the notion that agents may believe that large firms are less likely to go bankrupt, and Profitability, which presents a negative relation with leverage, what is predicted by the pecking order theory. Table 6 also presents the results of fixed and random effects estimation in order to compare the effects these more ordinary models return with the ones we get using dynamic ordered probit.

$$
\text { [ - insert Table } 6 \text { here - ] }
$$

In both fixed and random efects models capital structure determinants have almost the same directions as the ones in the dynamic ordered probit. Only Asset Tangibility, Profitability, and Z-score present different directions.

The size of the partial effects, that represents the economic significance of the capital structure determinants, is reported in Tables 7, 8, 9, and 10. Among the 1\% significant determinants the variable Growth and Investment Opportunities presents 
the highest impact in standard deviation terms; a standard deviation rise in this variable enhances the probability of a firm of being in the first ranges in 150.88 (68.22), 124.92 (32.44) and 97.28 (25.90) percentage points for the models with 5, 10 and 15 ranges respectively under the SNF (ISW) criterion. Asset tangibility also presents a relatively high partial effect, and the variables Depreciation and Amortization and Internal Reserves have little impact.

$$
\begin{aligned}
& \text { [ - insert Table } 7 \text { here - ] } \\
& \text { [ - insert Table } 8 \text { here - ] } \\
& \text { [ - insert Table } 9 \text { here - ] } \\
& {[\text { - insert Table } 10 \text { here - ] }}
\end{aligned}
$$

Tables 11, 12, and 13 present the marginal effects of the indicators of lagged dependent (discrete) variables for all three models under ISW criterion The behavior is consistent with the notion of dynamic rebalancing. The average firm is in low numbered ranges, therefore we can presume that the probability of the average firm of being in ranges with low leverages (such as Range 1) in period $t$ must increase if this firm was in a range with high leverage in period $t-1$. That happens in all three models. We can also see that the probability of a firm to stay in a low leveraged range given that it was already in a low leverage range in the previous period decreases, what may indicate inactivity when a firm is within its desired range.

$$
\begin{aligned}
& {[\text { - insert Table } 11 \text { here - ] }} \\
& {[\text { - insert Table } 12 \text { here - ] }} \\
& {[\text { - insert Table } 13 \text { here - ] }}
\end{aligned}
$$

The marginal effects of the indicators of the lagged dependent variables under the SNF criterion are similar to the ones in ISW. The partial effects of the indicator 
variable that represents the lagged dependent variable are in Tables 14, 15 and 16 for the models with 5,10 and 15 categories, respectively. What we see is that the lagged dependent variables that indicate low levels of leverage have a stronger impact lowering the probabilities of a firm be in a range with higher levels of leverage, i.e., it is less likely that a firm moves toward a higher range when it was in a low one in the previous period. Being in ranges with high leverages in $t-1$ increases the probability of lowering leverage in period $t$, what also seem to be consistent with rebalancing behavior.

$$
\begin{aligned}
& {[\text { - insert Table } 14 \text { here - ] }} \\
& {[\text { - insert Table } 15 \text { here - ] }} \\
& {[\text { - insert Table } 16 \text { here - ] }}
\end{aligned}
$$

\section{Testing the estimated models}

So far we have estimated six models, we know the marginal effects of each capital structure determinant in each model and we know which of these determinants are statistically relevant; now we want a way of checking if the estimates make sense. We perform two checks; first we do both in-sample and out-of-sample tests of pre-

dictability, then we estimate the inertia hypothesis suggested by Welch (2004) for the observations within the estimated target range and the ones outside of it.

\subsection{In-sample and out-of-sample predictability}

As we already mentioned, the estimated ranges can be loosely said to be optimal, the target a firm aims at, in the same sense the term optimal capital structure is used to describe the long-term debt-equity ratio, because they represent the long term 
average range controlled by a series of capital structure determinants. We know that firms are not always within their optimal ranges due to price shocks, even though we can assume that they are always within the non-recapitalization area, i.e., in the context of Figure 3 it is the area between lines $\underline{L}$ and $\bar{L}$. Hence, although firms will not always be within the optimal range we hope that the models we estimate have power to "predict" the range in which a firm will be within. Thus, we measure the proportion of times the estimated models correctly predict the range in which a firm is for the observations in-sample and out-of-sample.

The out-of-sample database consists of 174,168 observations ranging from 1951 to 2006 drawn from COMPUSTAT annual databank, in which we trimmed the observations according to their SIC codes, as described in section 2.2. The ranges with the same number of firms (SNF) were coded using the entire databank and them we excluded the observations that were in the sample used originally to estimate the models. The results are in Table 17, where one sees that the models with wider ranges present better predictive characteristics, what seems to happen because they may be as wide (or wider) than the non-recapitalization area for some firms. Thus, models with wider ranges will be correct more often than models in which firms depart from the target range. We can also draw insights about the consistency of the models, i.e., if the difference between the in-sample and the out-of-sample proportion of right predicted observations is small we can say that the model is consistent in the sense that its results are robust for a more diverse set of firms.

\section{[ - insert Table 17 here - ]}

The models estimated under SNF seem to be more consistent since their power of prediction does not vary so much for the out-of-sample test in comparison to the in sample test. However, the ISW criterion shows better ratios of correct predicted 
ranges in every case. It is probably better to set consistency as a criterion of adequateness for the models because these apparent superiority of the ISW criterion might be due to the low levels of leverage firms both in and out-of-sample present since for low levels of leverage the ISW criterion group more firms together (what can be seen in Tables 2 and 3).

\subsection{Inertia in and out of the optimal range}

We run an additional test based on the concept of inertia suggested by Welch (2004) to compare the models we estimate. The rationale described in figure 3 shows that when a firm is within its optimal range every change in its capital structure is due to price variation. When a firm is out of its optimal range but it is still within the non-recapitalization area the movements in the levels of leverage are also explained by changes in the price of equity, however, we expect firms to present a more active behavior than the one observed within the optimal range. Welch (2004) suggests that the variation in equity prices is the primary determinant of capital structure (what is known as inertia hypothesis). To test inertia hypothesis Welch (2004) estimates the following equation

$$
\frac{D_{t+k}}{D_{t+k}+E_{t+k}}=\alpha_{0}+\alpha_{1} \frac{D_{t}}{D_{t}+E_{t}}+\alpha_{2} \cdot \frac{D_{t}}{D_{t}+E_{t} \cdot\left(1+r_{t, t+k}\right)}+\varepsilon_{t, t+k}
$$

Where $D_{t}$ is the book value of debt, $E_{t}$ is the market value of equity, and $r_{t, t+k}$ is the percentage of change in the market value of equity between $t$ and $t+k$. If firms fail to rebalance their capital structures, as inertia hypothesis suggests, then $\alpha_{1}=0$ and $\alpha_{2}=1$. Welch (2004) estimates this model for many time horizons using ordinary least squares and the Fama-MacBeth method (1973). He finds that the estimated $\alpha_{2}$ is close to one and therefore concludes that the inertia hypothesis holds. Leary and 
Roberts (2005) shows, however, that this conclusion may be inaccurate since firms do not engage in continuous rebalance if adjustment is costly and therefore change in prices do have a high explanatory power since there is no active rebalancing within the non-recapitalization area (even if firms are out of the optimal range).

We estimate the same equation of Welch (2004) using the Fama-MacBeth (1973) estimation procedure (to be consistent with Welch (2004) and Leary and Roberts (2005)) for two subsamples; the ones within the calculated optimal range in period $t$ and the ones outside of it in period $t$. If firms are within their optimal range we expect that they will not engage in dynamic rebalancing until they reach one of the boundaries of the non-recapitalization area, which is wider than the optimal range. Therefore, if the calculated ranges are "optimal" we expect to see a stronger sign of inertia within and weaker evidence outside of them. If the calculated ranges are too wide or if they are not reflecting the adjustment behavior described in Figure 3 we expect that the evidence of inertia within and outside of the optimal ranges is not too different. So, we assume that there is inertia outside of the optimal range but we also assume that there are stronger signs of inertia within the optimal range. Thus, the use of the inertia hypothesis tests if the calculated target ranges make sense and also if firms are adjusting toward ranges instead of points, hence it is a joint hypothesis test. Welch's (2004) results are stronger for a one-year horizon, i.e., $k=1$, we restrict our attention to this one-year time horizon. Our formulation in terms of inner and outer range can be observed more explicitly if we rewrite equation 18 in the following way

$$
\begin{aligned}
& \frac{D_{t+1}}{D_{t+1}+E_{t+1}}=\alpha_{0}+\alpha_{1} \frac{D_{t}}{D_{t}+E_{t}}+\alpha_{2} \frac{D_{t}}{D_{t}+E_{t} \cdot\left(1+r_{t, t+1}\right)}+ \\
& +\delta t+\alpha_{3}\left(\delta t \cdot \frac{D_{t}}{D_{t}+E_{t}}\right)+\alpha_{4}\left(\delta t \cdot \frac{D_{t}}{D_{t}+E_{t} \cdot\left(1+r_{t, t+1}\right)}\right)+\varepsilon_{t, t+1}
\end{aligned}
$$

Where $\delta t$ is a dummy variable that equals 1 when the level of leverage of a firm 
is within the optimal calculated range in period $t$, and equals 0 otherwise. If $\alpha_{3}$ and $\alpha_{4}$ are significant it means that the difference between the observations in and outof-sample is significant. Furthermore, the values of $\alpha_{3}$ and $\alpha_{4}$ are also informative, they represent the difference between $\alpha_{1}$, which is the slope for the group out of the optimal range, and the slope for the observations within, which we define as $\alpha_{1}^{*}$, thus $\alpha_{3}$ is $\left(\alpha_{1}-\alpha_{1}^{*}\right)$, analogously, $\alpha_{4}$ is $\left(\alpha_{2}-\alpha_{2}^{*}\right)$. We focus our attention to $\alpha_{4}$ as Welch (2004) does with $\alpha_{2}$. Implicitly, we are not only testing if the estimated ranges make sense but we are also drawing evidence on how consistent the behavior of firms is with the notion of range-adjustment. The results of the estimation of equation 19 are in Table 18

\section{[ - insert Table 18 here - ]}

The estimated $\alpha_{4}$ is significant at the $5 \%$ level for the model with 10 ranges under the SNF criterion and is significant at the 1\% level for the model with 15 ranges, also under the SNF criterion. Therefore there is a stronger evidence of inertia within the estimated optimal ranges for these models. If the estimated target ranges indeed make sense this evidence also supports.the whole notion of range adjustment, i.e., firms seem to be more inert when their debt-equity ratios are interior points of a set of admissible levels, what is what we expect to see under range-adjustment behavior. This analysis reinforces the idea that the SNF criterion is more adequate, i.e., it seems that firms look at the market in order to choose the levels of debt and equity they issue. The other models do not show a significant difference between inertia within and out of the optimal range. 


\section{$5 \quad$ Final Remarks}

We estimate target leverage ranges, controlling for firm-specific characteristics and serial correlation, echoing recent evidence that suggests that firms do not have a unique desired level of leverage having instead a set of equally acceptable levels. We calculate coefficients and partial effects of six models, which have the same direction, similar size, and the same level of significance for most covariates, what we interpret as an indication of robustness. Surprisingly, firm size, volatility of cash flow, product uniqueness, market to book ratio and z-score are not statistically significant. Asset Tangibility, which is significant in the model, was supposed to have a positive impact on leverage, however, it present negative partial effects what is unexpected.

We also find evidence confirming range-adjustment behavior for some of the proxies of optimal range we calculate. We acknowledge, however, that the approach we adopt, i.e., Welch's (2004) model and Fama-MacBeth (1973) procedure, may influence the conclusions drawn about the adequateness of the model. Since we are implicitly testing a joint hypothesis, the estimation of the models we work with in this paper using a more diverse set of proxies for the optimal target range is a topic for future research. To use alternative ways of testing if these proxies are in accordance with the expected range-adjustment behavior is also a topic that can be further developed.

\section{Appendix}

\subsection{Appendix A: Adjustment costs and target range}

This appendix presents the conditions in which the adjustment toward ranges is optimal, following by Leary and Roberts (2005). They argue that the way firms 
rebalance their capital structures differ considerably according to the form of the adjustment costs they face. Basically, if the adjustment is costless, or if the adjustment cost function is strictly convex, the financing behavior will be continuous. This is not what an optimizer agent will choose to do if the costs are fixed or proportional to the adjustment size.

Models of dynamic optimization under different adjustment cost structures are not novel; they have been used in many different contexts (from investment policies and portfolio selection to inventory and cash management). Leary and Roberts mention Miller and Orr (1966), Caballero and Engle (1999), Constantinides (1979) and Fischer, Heinkel and Zechner (1989). As usual, the literature is quite vast in each area in which this question is dealt (for instance, inventory policy literature presents some models that result in conclusions and even in figures close to the ones we find here, see Ballou (1992) and Porteus (2002)). Figures 1, 2, and 3 illustrate the behavior of an optimizing agent for each cost structure considered in Leary and Robert's (2005) paper: (1) fixed cost, (2) proportional cost and (3) fixed plus weakly convex cost.

Figure 1 shows the results on the optimal control policy under the fixed cost structure, such as the one in Fischer, Heinkel and Zechner (1989). In this form of cost function the amount a firm has to pay to readjust its leverage is not determined by the size of the adjustment. This implies that when a firm needs to rebalance its capital structure it will do so by taking the leverage to the optimal-target level, therefore making large and infrequent adjustments.

Under this cost structure a firm will adjust its leverage towards its optimal level ( $L^{*}$, represented as the dotted line on the figure) at the moment it reaches one of the boundaries. $\underline{L}$ is the inferior boundary, the lowest level of leverage the firm admits, and $\bar{L}$ is the upper boundary, the highest level of leverage tolerated (these boundaries 
are represented by lines on the figure). The boundaries can also be seen as the point in which the benefits from adjusting the leverage outweigh the costs.

The proportional cost is presented in Figure 2. Under this cost structure, whenever a firm reaches one of its boundaries (again represented by the lines $\underline{L}$ and $\bar{L}$ on the figure) it will make small adjustments to remain in the no-recapitalization region, i.e., the region between $\underline{L}$ and $\bar{L}$. The intuition behind this behavior is that every time a firm needs to raise money it has to pay for each additional dollar raised, therefore the size of the adjustment is small. Another feature of this cost structure is that the readjustments are quite clustered because what takes the leverage to a level close to one of its boundaries in our simulation is the variation of a firm's stock prices, and once the leverage reaches the upper or to the lower boundary it will stay around this level because of the small adjustments the firm does, eventually departing from this level due to price shocks.

Figure 3 represents the case we are interested in our paper. This cost function is composed by a fixed and weakly convex part. This structure has an optimal policy that is a mix of the two we illustrate in Figures 1 and 2. A firm readjusts its leverage towards a level in the way between the fixed cost and the proportional cost optima. This level is denoted by the region between the dotted lines in Figure 3 and the readjustment will aim at one of the admissible levels $\left(\underline{L}^{*}\right.$ or $\left.\bar{L}^{*}\right)$. From that point on the firm will remain inactive and changes in leverage will be due to stock price variations. For that reason, the region between $\underline{L}^{*}$ or $\bar{L}^{*}$ is the "target range" to which the firm adjusts. 


\subsection{Appendix B: Likelihood function}

In order to derive the log-likelihood function we follow the structure implemented by Butler and Moffitt (1982). The following set of equations describes the model we want to estimate

$$
\begin{aligned}
y_{i t}^{*} & =\mathbf{x}_{i t} \beta+\varepsilon_{i t} \\
\varepsilon_{i t} & =a_{i}+e_{i t} \\
\operatorname{Var}\left(\varepsilon_{i t} \mid \mathbf{X}\right) & =\sigma_{a}^{2}+\sigma_{e}^{2}=\sigma_{a}^{2}+1 \\
\operatorname{Cov}\left(\varepsilon_{i t}, \varepsilon_{i s} \mid \mathbf{X}\right) & =\rho=\frac{\sigma_{a}^{2}}{1+\sigma_{a}^{2}}
\end{aligned}
$$

Where $\mathbf{X}$ indicates all the exogenous data in the sample $\mathbf{x}_{i t}$ for all $i$ and $t$. We do not observe $y_{i t}^{*}$, instead we observe

$$
\begin{aligned}
& y_{i t}=0 \quad \text { if } \quad y_{i t}^{*} \leq \mu_{1} \\
& y_{i t}=1 \quad \text { if } \quad \mu_{1} \leq y_{i t}^{*} \leq \mu_{2} \\
& \vdots \\
& y_{i t}=J \quad \text { if } \quad y_{i t}^{*}>\mu_{J-1}
\end{aligned}
$$

Where $\mu_{1}<\mu_{2}<\cdots<\mu_{J}$ are unknown cut points, or threshold parameters.

We want to derive the joint probability of firm $i$ for all $T$ observations $P\left(y_{i 1}, \ldots, y_{i T}\right)$. We start by deriving the joint density of the $e_{i t}$ by integrating $a_{i}$ out of the joint density of $\left(\varepsilon_{i 1}, \ldots, \varepsilon_{i T}, a_{i}\right)$ (what is possible due to the nature of the random effects model) which is:

$$
\phi\left(\varepsilon_{i 1}, \ldots, \varepsilon_{i T}, a_{i}\right)=\phi\left(\varepsilon_{i 1}, \ldots, \varepsilon_{i T} \mid a_{i}\right)
$$


Where $\phi(\cdot)$ represents the p.d.f. of the normal distribution function. We have, therefore, that

$$
\phi\left(\varepsilon_{i 1}, \ldots, \varepsilon_{i T}\right)=\int_{-\infty}^{+\infty} \phi\left(\varepsilon_{i 1}, \ldots, \varepsilon_{i T} \mid a_{i}\right) \phi\left(a_{i}\right) d a_{i}
$$

In this way the $\varepsilon_{i t}$ 's are independent (conditioned on $a_{i}$ ), so

$$
\phi\left(\varepsilon_{i 1}, \ldots, \varepsilon_{i T}, a_{i}\right)=\int_{-\infty}^{+\infty} \prod_{t=1}^{T} \phi\left(\varepsilon_{i t} \mid a_{i}\right) \phi\left(a_{i}\right) d a_{i}
$$

Generalizing the joint probability suggested by Butler and Moffitt (1982) for $y_{i t}=j$ we define

$$
\begin{aligned}
& d_{i t}=\mu_{j-1}-\mathbf{x}_{i t} \beta \\
& s_{i t}=\mu_{j}-\mathbf{x}_{i t} \beta
\end{aligned}
$$

And then

$$
\begin{aligned}
P\left(y_{i 1}, \ldots, y_{i T}\right) & =\int_{d_{i 1}}^{s_{i 1}} \ldots \int_{d_{i t}}^{s_{i t}} \phi\left(\varepsilon_{i 1}, \ldots, \varepsilon_{i T}\right) d \varepsilon_{i T} \ldots d \varepsilon_{i 1}= \\
& =\int_{d_{i 1}}^{s_{i 1}} \cdots \int_{d_{i t}}^{s_{i t}} \int_{-\infty}^{+\infty} \prod_{t=1}^{T} \phi\left(e_{i t} \mid a_{i}\right) d a_{i} d e_{i T} \ldots d e_{i 1} \\
& =\int_{-\infty}^{+\infty} \prod_{t=1}^{T}\left[\Phi\left(s_{i t} \mid a_{i}\right)-\Phi\left(d_{i t} \mid a_{i}\right)\right] d a_{i}
\end{aligned}
$$

In which $\Phi(\cdot)$ represents the c.d.f. of the normal distribution function. The log-likelihood function, which is

$$
L_{i}=\sum_{i=1}^{N} \ln \left[P\left(y_{i 1}, \ldots, y_{i T}\right)\right]
$$

is found by plugging equation 20 in 21 . 


\subsection{Appendix C: Definition of variables}

In this Appendix we define the capital structure determinants, and also the marketdebt equity ratio, in terms of their COMPUSTAT items, which are in parenthesis.

- Asset tangibility: Asset to property plant and equipment (7)/Total Assets (6)

- Depreciation and Amortization: Depreciation and Amortization (14)/Total As$\operatorname{sets}(6)$

- Firm Size: Firm sales in $t(12) /$ Total sales of sample in $t$

- Growth/Inv opportunities: Capex in $t+1$ (128)/Total Assets (6)

- Internal Reserves: Cash and marketable securities (1)/Total Assets

- Market to book ratio: (Total Assets (6)-Book Equity (216) + Market Value $\left.\left(25^{*} 199\right)\right) /$ Total Assets (6)

- Product Uniqueness: Selling Expenses (189)/Total Sales (12)

- Profitability: After tax Operating Income (13-14-16)/Total Assets

- Volatility of cash flow: (Net income $t$ (172) - Net income $t-1$ )/Total Assets (6)

- Z-Score: $3.3^{*}($ EBIT $(18+15+16)+$ Sales $(12))+1.4^{*}$ Retained Earnings $(36)+1.2^{*}$ Working Capital (4-5)

- Market debt-equity ratio: Total Debt $(9+34) /($ Total Debt $(9+34)+$ Market Value (Market Value $\left(25^{*} 199\right)$ ) 


\subsection{Appendix D: Intercept in ordered probit models}

The intercept is implicit in the cut points in ordered probit models. To see that more clearly take a three-outcome ordered probit model, the response probabilities are

$$
\begin{aligned}
& P\left(y_{i t}=1 \mid \mathbf{x}_{i t}\right)=P\left(\mathbf{x}_{i t} \beta+\varepsilon_{i t} \leq \mu_{1} \mid \mathbf{x}_{i t}\right) \\
& P\left(y_{i t}=2 \mid \mathbf{x}_{i t}\right)=P\left(\mu_{1}<\mathbf{x}_{i t} \beta+\varepsilon_{i t} \leq \mu_{2} \mid \mathbf{x}_{i t}\right) \\
& P\left(y_{i t}=3 \mid \mathbf{x}_{i t}\right)=P\left(\mathbf{x}_{i t} \beta+\varepsilon_{i t}>\mu_{2} \mid \mathbf{x}_{i t}\right)
\end{aligned}
$$

If we add an intercept (alternatively, if we consider that the intercept already was in $\mathbf{x}_{i t}$ and we now write it explicitly)

$$
\begin{aligned}
& P\left(y_{i t}=1 \mid \mathbf{x}_{i t}\right)=P\left(\mathbf{x}_{i t} \beta+\alpha_{0}+\varepsilon_{i t} \leq \mu_{1} \mid \mathbf{x}_{i t}\right) \\
& P\left(y_{i t}=2 \mid \mathbf{x}_{i t}\right)=P\left(\mu_{1}<\mathbf{x}_{i t} \beta+\alpha_{0}+\varepsilon_{i t} \leq \mu_{2} \mid \mathbf{x}_{i t}\right) \\
& P\left(y_{i t}=3 \mid \mathbf{x}_{i t}\right)=P\left(\mathbf{x}_{i t} \beta+\alpha_{0}+\varepsilon_{i t}>\mu_{2} \mid \mathbf{x}_{i t}\right)
\end{aligned}
$$

Which is the same of

$$
\begin{aligned}
& P\left(y_{i t}=1 \mid \mathbf{x}_{i t}\right)=P\left(\mathbf{x}_{i t} \beta+\varepsilon_{i t} \leq \mu_{1}-\alpha_{0} \mid \mathbf{x}_{i t}\right) \\
& P\left(y_{i t}=2 \mid \mathbf{x}_{i t}\right)=P\left(\mu_{1}<\mathbf{x}_{i t} \beta+\varepsilon_{i t} \leq \mu_{2}-\alpha_{0} \mid \mathbf{x}_{i t}\right) \\
& P\left(y_{i t}=3 \mid \mathbf{x}_{i t}\right)=P\left(\mathbf{x}_{i t} \beta+\varepsilon_{i t}>\mu_{2}-\alpha_{0} \mid \mathbf{x}_{i t}\right)
\end{aligned}
$$

Thus, $\mu_{1}, \mu_{2}$ and $\alpha_{0}$ are collinear, the only difference is in the estimation of the threshold parameters, and therefore there is no use for an intercept. Actually, the cut points are analogue to intercepts. Consider a two-outcome probit model 


$$
\begin{aligned}
& P\left(y_{i t}=1 \mid \mathbf{x}_{i t}\right)=P\left(\mathbf{x}_{i t} \beta+\varepsilon_{i t} \leq \mu_{1} \mid \mathbf{x}_{i t}\right) \\
& P\left(y_{i t}=2 \mid \mathbf{x}_{i t}\right)=P\left(\mathbf{x}_{i t} \beta+\varepsilon_{i t}>\mu_{1} \mid \mathbf{x}_{i t}\right)
\end{aligned}
$$

This can be re-written as

$$
\begin{aligned}
P\left(y_{i t}\right. & \left.=1 \mid \mathbf{x}_{i t}\right)=1-P\left(y_{i t}=2 \mid \mathbf{x}_{i t}\right) \\
P\left(y_{i t}\right. & \left.=2 \mid \mathbf{x}_{i t}\right)=P\left(\mu_{1}<\mathbf{x}_{i t} \beta+\varepsilon_{i t} \mid \mathbf{x}_{i t}\right)=P\left(0<\mathbf{x}_{i t} \beta-\mu_{1}+\varepsilon_{i t} \mid \mathbf{x}_{i t}\right)= \\
& =P\left(\mathbf{x}_{i t} \beta-\mu_{1}+\varepsilon_{i t}>0 \mid \mathbf{x}_{i t}\right)
\end{aligned}
$$

In this case $\mu_{1}$ is the intercept. Therefore, although the intercept may not be explicitly considered in the model, they are implicitly added in the estimation of the cut points.

\section{References}

ARPING, S.; LORANTH, G. Corporate Leverage and Product Differentiation Strategy. Journal of Business 79, 3175- 3207, 2006.

BAKER, M.; WURGLER, J. Market timing and capital structure. Journal of Finance 57, 1-30, 2002.

BALLOU, R.Business Logistics Management, Prentice Hall, 1992.

BUTLER, R.; MOFFIT, R. A computationally efficient quadrature procedure for the one factor multinomial probit model, Econometrica, 50, 761-764, 1982. 
CABALLERO, R.; ENGLE, E. Explaining investment dynamics in the U.S. manufacturing: A generalized(S,s) approach, Econometrica 67, 783-826, 1999.

CONSTATINIDES, G. Multiperiod consumption and investment behavior with convex transaction costs, Management Science 25, 1127-137, 1979.

FAMA, E.; FRENCH, K. Testing tradeoff and pecking order predictions about dividends and debt, The Review of Financial Studies 15, 1-33, 2002.

FAMA, E.; MACBETH, J. Risk, return, and equilibrium: Empirical tests, Journal of Political Economy 81, 607-636, 1973.

FISCHER, E.; HEINKEL, R; ZECHNER, J. Dynamic capital structure choice: Theory and tests, Journal of Finance 44, 19-40, 1989.

FLANNERY, M.; RANGAN, K. Partial adjustment toward target capital structures, Journal of Financial Economics 79, 469-506, 2006.

FRANK, M.; GOYAL, V. Testing the pecking order theory of capital structure, Journal of Financial Economics 67, 217-248, 2003.

GRAHAM, J.; HARVEY, C. The theory and practice of corporate finance: Evidence from the field, Journal of Financial Economics 60, 186-243, 2001.

GREENE, W.; HEnsheR, D. Modeling Ordered Choices: A Primer and Recent Developments, 2008, Available at SSRN: http://ssrn.com/abstract=1213093

HARRIS, M.; RAVIV, A. The theory of capital structure, Journal of Finance 46, 297-355, 1991.

HARTER, H. Another look at plotting positions, Communications in Statistics, Theory and Methods 13, 1613-1633, 1984. 
HOVAKIMIAN, A.; LI, G. Do Firms Have Unique Target Debt Ratios to Which They Adjust?, 2009, Available at SSRN: http://ssrn.com/abstract=1138316.

KAYHAN, A.; TITMAN, S. Firms' histories and their capital structures, Journal of Financial Economics 83, 1-32, 2007.

LEARY, M.; ROBERTS, M. Do firms rebalance their capital structures?", Journal of Finance 60, 2575-2619, 2005.

LEMMON, M.; ROBERTS, M.; ZENDER, J. Back to the beginning: Persistence and the Cross-Section of Corporate Capital Structure, Journal of Finance (forthcoming), 2006.

MILLER, M.; ORR, D. A model of demand for money by firms", Quarterly Journal of Economics 80, 413-435, 1966.

MINTON, B.; SCHRAND, C The impact of cash flow volatility on discretionary investment and the costs of debt and equity financing, Journal of Financial Economics 54, 423-460, 1999.

MODIGLIANI, F.; MILLER, M. The cost of capital, corporate financing, and the theory of investment, American Economic Review 48, 655-669, 1958.

MYERS, S. The capital structure puzzle, Journal of Finance, 39, 575-592, 1984.

MYERS, S. Capital structure, Journal of Economic Perspectives 15, 81-102, 2001.

MYERS, S.; MAJLUF, N. Corporate financing and investment decision when firms have information that investors do not have, Journal of Financial Economics 13, 187-221, 1984. 
OPLER, T.; SHERIDAN, T. Financial distress and corporate performance, Journal of Finance 49, 1015-40, 1994.

PORTEUS, E. Foundations of stochastic inventory theory, Stanford University Press, 2002.

RAJAN, R.; ZINGALES, L. What do we know about capital structure: Some evidence from international data, Journal of Finance 50, 1421-1460, 1995.

SHYAM-SUNDER, L.; MYERS, S. Testing static tradeoff against pecking order models of capital structure, Journal of Financial Economics 51, 219-243, 1999.

WELCH, I. Capital structure and stock returns, Journal of Political Economy 112, 106-131, 2004.

WOOLDRIDGE, J. Econometric Analysis of Cross Section and Panel Data, MIT Press, 2001.

WOOLDRIDGE, J. Simple solutions to the initial conditions problem in dynamic, nonlinear panel data models with unobserved heterogeneity, Journal of Applied Econometrics 20, 39-54, 2005. 
Figure 1. Fixed Cost: The figure presents simulated data on the recapitalization behavior when adjustment costs are fixed. When leverage reaches (or crosses) one of the boundaries $(\bar{L}$ or $\underline{L})$ a firm readjusts leverage to its initial value $\left(L^{*}\right)$.

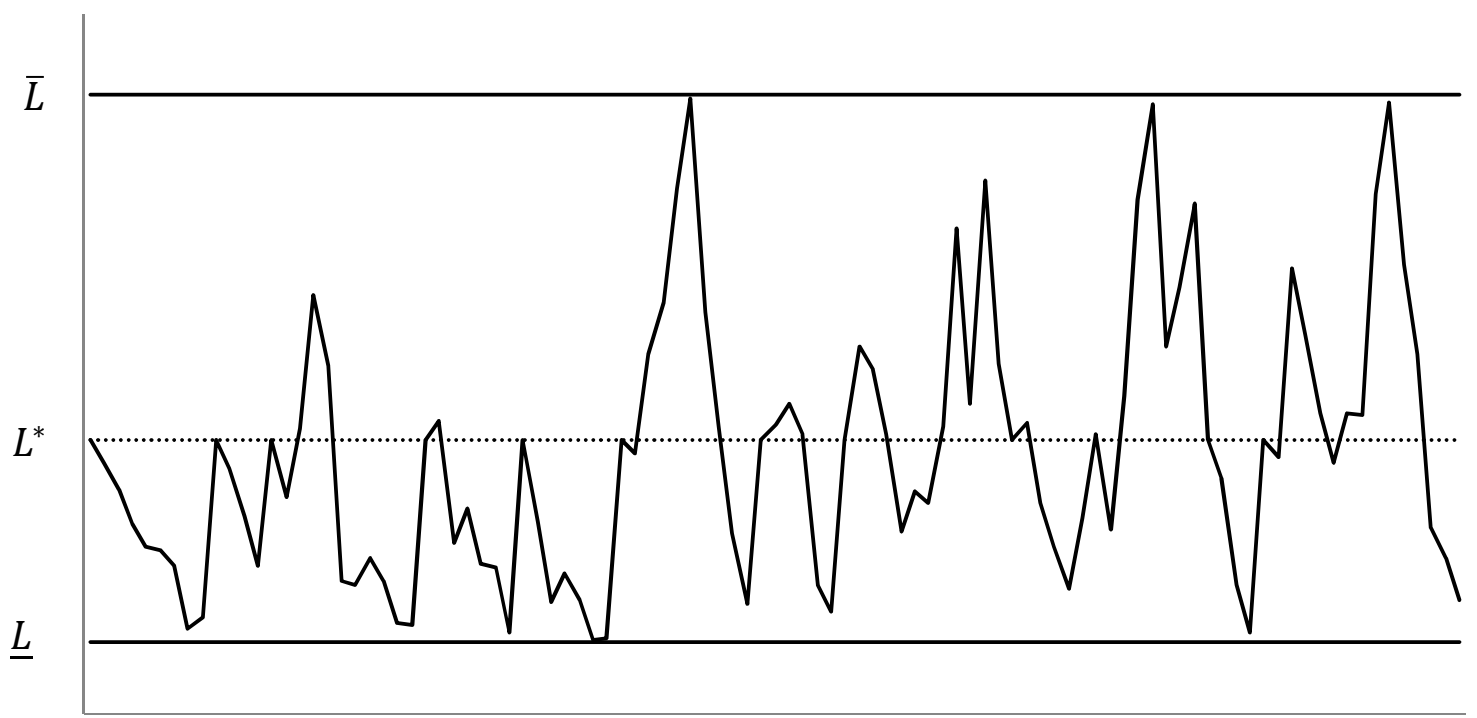

Figure 2. Proportional Cost: The figure presents simulated data on the recapitalization behavior when adjustment costs are proportional. When leverage reaches (or crosses) one of the boundaries $(\bar{L}$ or $\underline{L})$ a firm readjusts leverage to its one of its nearest boundaries $(\bar{L}$ or $\underline{L})$.

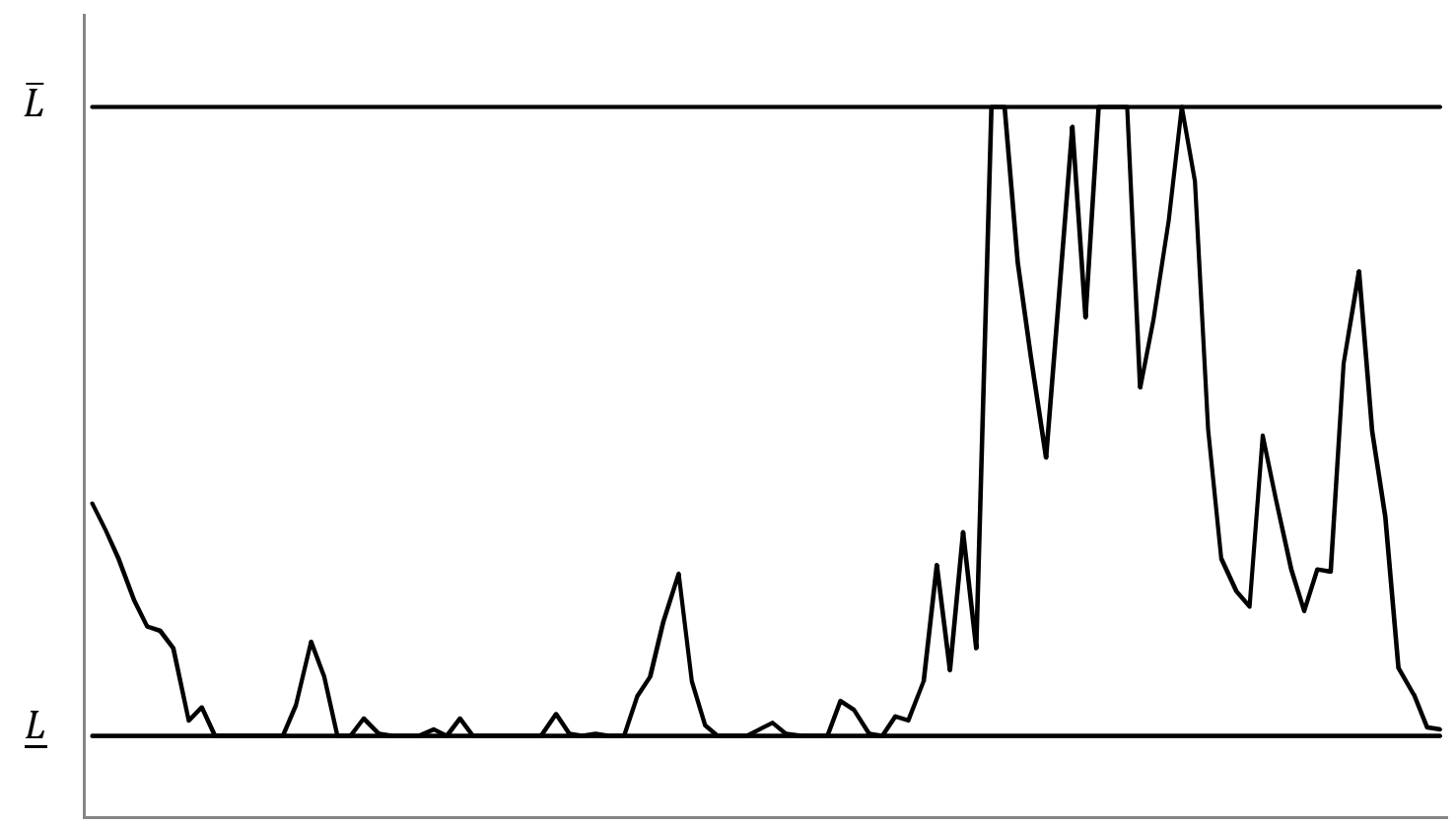


Figure 3. Fixed and Weakly Convex Cost: The figure presents simulated data on the recapitalization behavior when adjustment costs are fixed and weakly convex. When leverage reaches (or crosses) one of the boundaries $(\bar{L}$ or $\underline{L}$ ) a firm readjusts leverage to an interior point of the optimal leverage range $\left(\underline{L}^{*}\right.$ or $\left.\bar{L}^{*}\right)$.

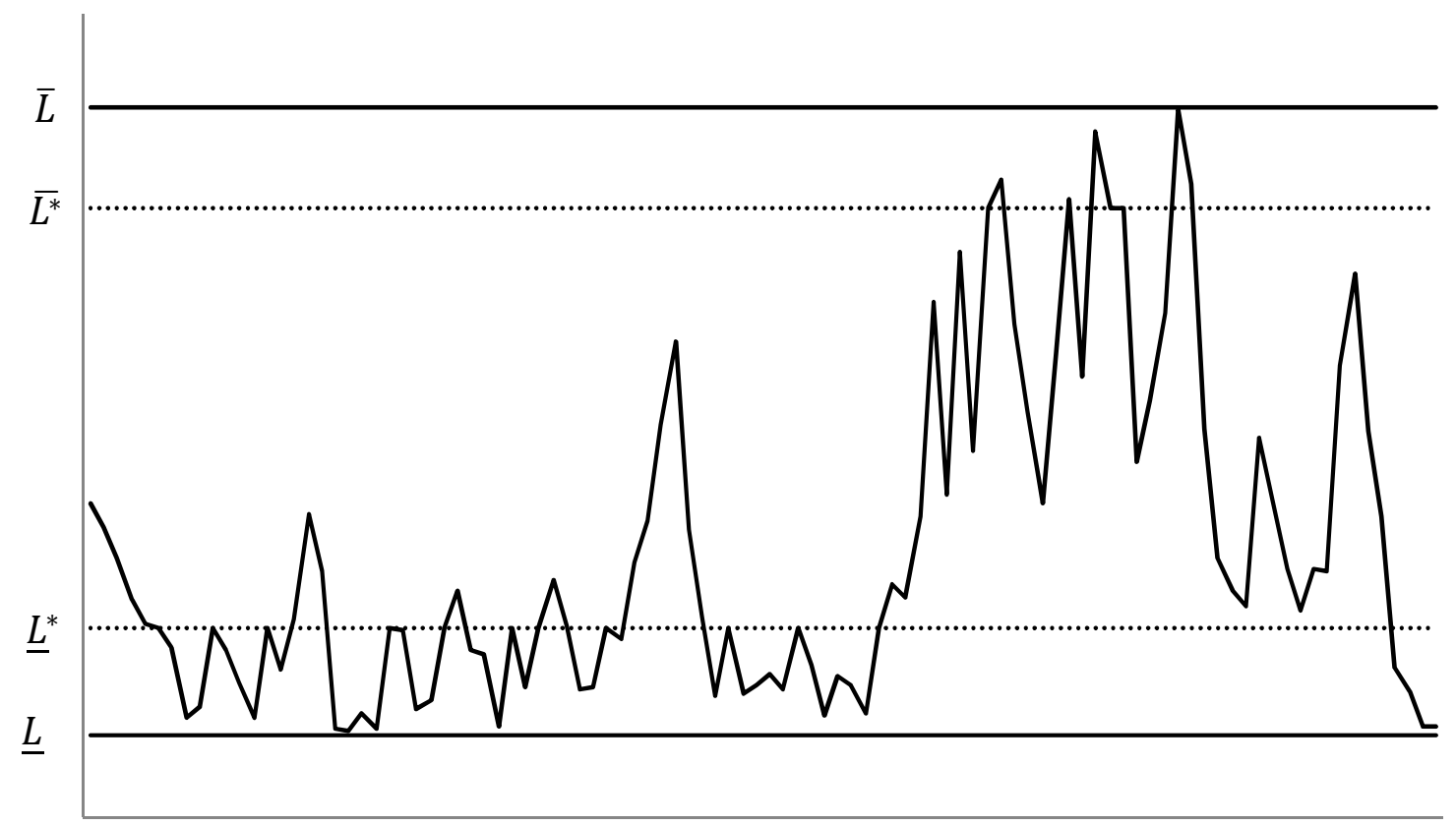




\section{Figure 4. Distribution of the levels of leverage}

The figure presents the distribution of the levels of leverage, measured by market debt-equity ratio, over a sample of all firms (except financial and regulated ones) drawn from annual COMPUSTAT from 1991 to 2006. The bars indicate the concentration of firms in each category (we choose 10 categories for illustration) and the line corresponds to the expected normal distribution that was over the same data.

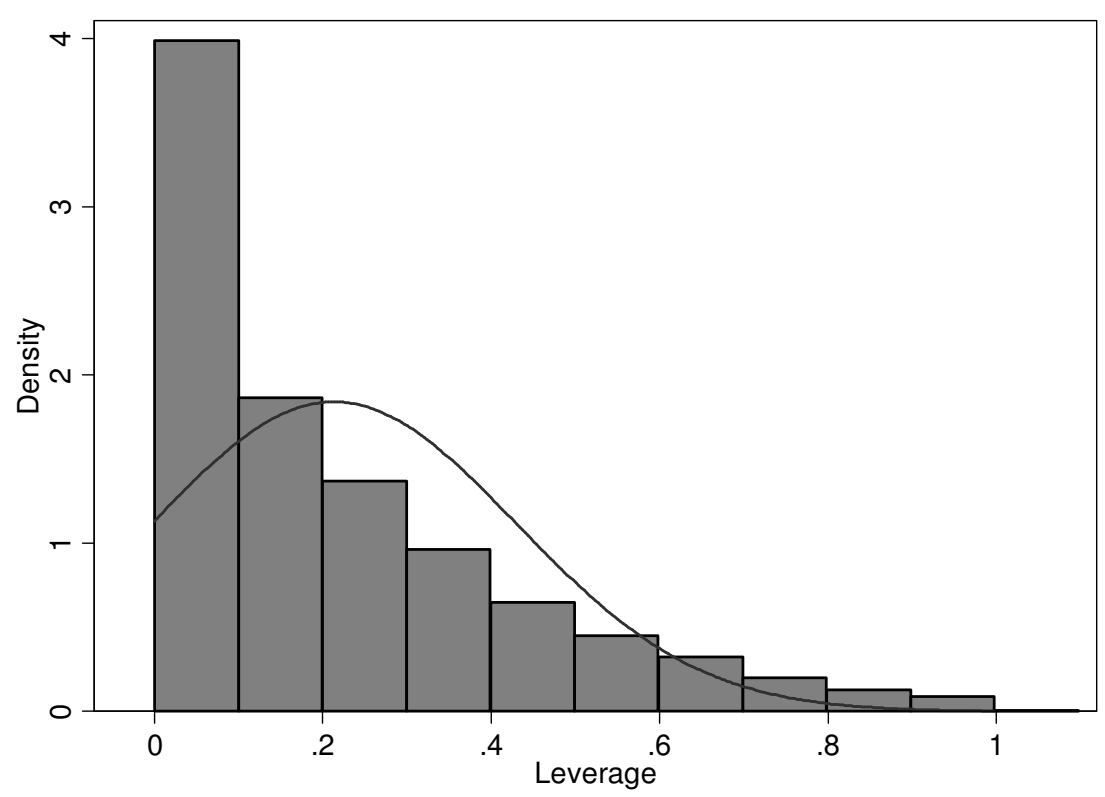

\section{Table 1. Level of leverage}

This table displays summary statistics for the market debt-equity ratio, the measure of leverage we adopt in this paper. Sampled firms exclude financial institutions (SIC's 6000-6999) and regulated firms (SICs 4900-4999).

St.

Obs. Mean Deviation Median Min Max

\begin{tabular}{lllllll} 
Debt-Equity Ratio & 19,168 & 0.21 & 0.22 & 0.15 & 0 & 1 \\
\hline
\end{tabular}


Table 2. Descriptive statistics of ranges generated by breaking the level of leverage in intervals of the same width (ISW): This table displays the mean level of leverage, standard deviation, number of observations, the proportion of these observations relative to the total number of firms within each range and the minimum and maximum level of leverage of each range for all three amounts of ranges in which we are breaking the data. The procedure we use to get the discrete variable indicating the ranges reported in this table consists of breaking the market debt-equity ratio into intervals of the same width. We repeat this process generating 5, 10 and 15 categories.

\begin{tabular}{|c|c|c|c|c|c|c|c|c|c|c|c|c|}
\hline \multirow{3}{*}{ Range } & \multicolumn{4}{|c|}{5 Categories } & \multicolumn{4}{|c|}{10 Categories } & \multicolumn{4}{|c|}{15 Categories } \\
\hline & $\begin{array}{c}\text { Mean } \\
\text { Leverage }\end{array}$ & Obs. & & & $\begin{array}{c}\text { Mean } \\
\text { Leverage }\end{array}$ & Obs. & & & $\begin{array}{c}\text { Mean } \\
\text { Leverage }\end{array}$ & Obs. & & \\
\hline & $\begin{array}{c}\text { (St. } \\
\text { Deviation) }\end{array}$ & $\begin{array}{c}\text { (Frequency } \\
\%)\end{array}$ & Min & Max & $\begin{array}{c}\text { (St. } \\
\text { Deviation) }\end{array}$ & $\begin{array}{c}\text { (Frequency } \\
\%)\end{array}$ & Min & Max & $\begin{array}{c}\text { (St. } \\
\text { Deviation) }\end{array}$ & $\begin{array}{c}\text { (Frequency } \\
\%)\end{array}$ & Min & Max \\
\hline 1 & $\begin{array}{c}0.07 \\
(0.06)\end{array}$ & $\begin{array}{l}11,208 \\
(58 \%)\end{array}$ & 0.00 & 0.20 & $\begin{array}{c}0.03 \\
(0.03)\end{array}$ & $\begin{array}{l}7,635 \\
(40 \%)\end{array}$ & 0.00 & 0.1 & $\begin{array}{c}0.02 \\
(0.02)\end{array}$ & $\begin{array}{l}6,230 \\
(33 \%)\end{array}$ & 0.00 & 0.07 \\
\hline 2 & $\begin{array}{c}0.29 \\
(0.06)\end{array}$ & $\begin{array}{l}4,460 \\
(23 \%)\end{array}$ & 0.20 & 0.40 & $\begin{array}{c}0.15 \\
(0.03)\end{array}$ & $\begin{array}{l}3,573 \\
(19 \%)\end{array}$ & 0.1 & 0.2 & $\begin{array}{c}0.1 \\
(0.02)\end{array}$ & $\begin{array}{l}2,741 \\
(14 \%)\end{array}$ & 0.07 & 0.13 \\
\hline 3 & $\begin{array}{c}0.49 \\
(0.06)\end{array}$ & $\begin{array}{l}2,103 \\
(11 \%)\end{array}$ & 0.40 & 0.60 & $\begin{array}{c}0.25 \\
(0.03)\end{array}$ & $\begin{array}{l}2,624 \\
(14 \%)\end{array}$ & 0.2 & 0.3 & $\begin{array}{c}0.16 \\
(0.02)\end{array}$ & $\begin{array}{l}2,237 \\
(12 \%)\end{array}$ & 0.13 & 0.20 \\
\hline 4 & $\begin{array}{c}0.68 \\
(0.06)\end{array}$ & $\begin{array}{l}988 \\
(5 \%)\end{array}$ & 0.60 & 0.80 & $\begin{array}{c}0.35 \\
(0.03)\end{array}$ & $\begin{array}{l}1,836 \\
(10 \%)\end{array}$ & 0.3 & 0.4 & $\begin{array}{c}0.23 \\
(0.02)\end{array}$ & $\begin{array}{l}1,872 \\
(10 \%)\end{array}$ & 0.20 & 0.27 \\
\hline 5 & $\begin{array}{c}0.89 \\
(0.05)\end{array}$ & $\begin{array}{l}409 \\
(2 \%)\end{array}$ & 0.80 & 1.00 & $\begin{array}{c}0.45 \\
(0.03)\end{array}$ & $\begin{array}{l}1,239 \\
(6 \%)\end{array}$ & 0.4 & 0.5 & $\begin{array}{c}0.3 \\
(0.02)\end{array}$ & $\begin{array}{l}1,424 \\
(7 \%)\end{array}$ & 0.27 & 0.33 \\
\hline 6 & & & & & $\begin{array}{c}0.55 \\
(0.03)\end{array}$ & $\begin{array}{l}864 \\
(5 \%)\end{array}$ & 0.5 & 0.6 & $\begin{array}{c}0.36 \\
(0.02)\end{array}$ & $\begin{array}{l}1,164 \\
(6 \%)\end{array}$ & 0.33 & 0.40 \\
\hline 7 & & & & & $\begin{array}{c}0.65 \\
(0.03)\end{array}$ & $\begin{array}{c}612 \\
(3 \%)\end{array}$ & 0.6 & 0.7 & $\begin{array}{c}0.43 \\
(0.02)\end{array}$ & $\begin{array}{l}874 \\
(5 \%)\end{array}$ & 0.40 & 0.47 \\
\hline 8 & & & & & $\begin{array}{c}0.74 \\
(0.03)\end{array}$ & $\begin{array}{l}376 \\
(2 \%)\end{array}$ & 0.7 & 0.8 & $\begin{array}{c}0.5 \\
(0.02)\end{array}$ & $\begin{array}{c}687 \\
(4 \%)\end{array}$ & 0.47 & 0.53 \\
\hline 9 & & & & & $\begin{array}{c}0.85 \\
(0.03)\end{array}$ & $\begin{array}{l}244 \\
(1 \%)\end{array}$ & 0.8 & 0.9 & $\begin{array}{c}0.57 \\
(0.02)\end{array}$ & $\begin{array}{l}542 \\
(3 \%)\end{array}$ & 0.53 & 0.60 \\
\hline 10 & & & & & $\begin{array}{c}0.94 \\
(0.03)\end{array}$ & $\begin{array}{c}165 \\
(1 \%)\end{array}$ & 0.9 & 1 & $\begin{array}{c}0.63 \\
(0.02)\end{array}$ & $\begin{array}{l}440 \\
(2 \%)\end{array}$ & 0.60 & 0.67 \\
\hline 11 & & & & & & & & & $\begin{array}{c}0.7 \\
(0.02)\end{array}$ & $\begin{array}{l}331 \\
(2 \%)\end{array}$ & 0.67 & 0.73 \\
\hline 12 & & & & & & & & & $\begin{array}{c}0.76 \\
(0.02)\end{array}$ & $\begin{array}{c}217 \\
(1 \%)\end{array}$ & 0.73 & 0.80 \\
\hline 13 & & & & & & & & & $\begin{array}{c}0.83 \\
(0.02)\end{array}$ & $\begin{array}{c}174 \\
(1 \%)\end{array}$ & 0.80 & 0.87 \\
\hline 14 & & & & & & & & & $\begin{array}{c}0.9 \\
(0.02)\end{array}$ & $\begin{array}{c}135 \\
(1 \%)\end{array}$ & 0.87 & 0.93 \\
\hline 15 & & & & & & & & & $\begin{array}{c}0.96 \\
(0.02)\end{array}$ & $\begin{array}{c}100 \\
(1 \%)\end{array}$ & 0.93 & 1.00 \\
\hline
\end{tabular}


Table 3. Descriptive statistics of ranges generated by breaking the level of leverage in intervals with the same number of firms (SNF): This table displays the mean level of leverage, standard deviation, number of observations, the proportion of these observations relative to the total number of firms within each range and the minimum and maximum level of leverage of each range for all three amounts of ranges in which we are breaking the data. The procedure we use to get the discrete variable indicating the ranges reported in this table consists of ranking firms according to their plotting position and then breaking this measure in order to get intervals with the same number of firms each. We repeat this process generating 5, 10 and 15 categories.

\begin{tabular}{|c|c|c|c|c|c|c|c|c|c|c|c|c|}
\hline \multirow{3}{*}{ Range } & \multicolumn{4}{|c|}{5 Categories } & \multicolumn{4}{|c|}{10 Categories } & \multicolumn{4}{|c|}{15 Categories } \\
\hline & \multirow{2}{*}{$\begin{array}{c}\text { Mean } \\
\text { (St. } \\
\text { Deviation) }\end{array}$} & \multicolumn{2}{|l|}{ Obs. } & \multirow[b]{2}{*}{ Max } & \multirow{2}{*}{$\begin{array}{c}\text { Mean } \\
\text { (St. } \\
\text { Deviation) }\end{array}$} & \multicolumn{2}{|l|}{ Obs. } & \multirow[b]{2}{*}{ Max } & \multirow{2}{*}{$\begin{array}{c}\text { Mean } \\
\text { (St. } \\
\text { Deviation) }\end{array}$} & Obs. & \multirow[b]{2}{*}{ Min } & \multirow[b]{2}{*}{$\operatorname{Max}$} \\
\hline & & $\begin{array}{c}\text { (Frequency } \\
\%)\end{array}$ & Min & & & $\begin{array}{c}\text { (Frequency } \\
\%)\end{array}$ & Min & & & $\begin{array}{c}\text { (Frequency } \\
\%)\end{array}$ & & \\
\hline \multirow[t]{2}{*}{1} & 0.00 & 3,824 & 0.00 & 0.03 & 0.00 & 1,487 & 0.00 & 0.00 & 0.00 & 1,483 & 0.00 & 0.00 \\
\hline & $(0.00)$ & $(20 \%)$ & & & $(0.00)$ & $(8 \%)$ & & & $(0.00)$ & $(8 \%)$ & & \\
\hline \multirow[t]{2}{*}{2} & 0.06 & 3,840 & 0.01 & 0.14 & 0.01 & 1,920 & 0.00 & 0.03 & 0.00 & 1,120 & 0.00 & 0.00 \\
\hline & $(0.03)$ & $(20 \%)$ & & & $(0.01)$ & $(10 \%)$ & & & $(0.00)$ & $(6 \%)$ & & \\
\hline \multirow[t]{2}{*}{3} & 0.15 & 3,840 & 0.08 & 0.28 & 0.03 & 1,920 & 0.01 & 0.08 & 0.01 & 1,221 & 0.00 & 0.03 \\
\hline & $(0.04)$ & $(20 \%)$ & & & $(0.01)$ & $(10 \%)$ & & & $(0.01)$ & $(6 \%)$ & & \\
\hline \multirow[t]{2}{*}{4} & 0.29 & 3,840 & 0.17 & 0.48 & 0.08 & 1,920 & 0.04 & 0.14 & 0.03 & 1,280 & 0.01 & 0.06 \\
\hline & $(0.07)$ & $(20 \%)$ & & & $(0.02)$ & $(10 \%)$ & & & $(0.01)$ & $(7 \%)$ & & \\
\hline \multirow[t]{2}{*}{5} & 0.56 & 3,824 & 0.29 & 1.00 & 0.13 & 1,920 & 0.08 & 0.20 & 0.06 & 1,280 & 0.03 & 0.10 \\
\hline & $(0.16)$ & $(20 \%)$ & & & $(0.03)$ & $(10 \%)$ & & & $(0.01)$ & $(7 \%)$ & & \\
\hline \multirow[t]{2}{*}{6} & & & & & 0.18 & 1,920 & 0.12 & 0.28 & 0.09 & 1,280 & 0.06 & 0.14 \\
\hline & & & & & $(0.04)$ & $(10 \%)$ & & & $(0.02)$ & $(7 \%)$ & & \\
\hline \multirow[t]{2}{*}{7} & & & & & 0.25 & 1,920 & 0.17 & 0.36 & 0.12 & 1,280 & 0.08 & 0.18 \\
\hline & & & & & $(0.05)$ & $(10 \%)$ & & & $(0.02)$ & $(7 \%)$ & & \\
\hline \multirow[t]{2}{*}{8} & & & & & 0.33 & 1,920 & 0.22 & 0.48 & 0.15 & 1,280 & 0.10 & 0.22 \\
\hline & & & & & $(0.06)$ & $(10 \%)$ & & & $(0.03)$ & $(7 \%)$ & & \\
\hline \multirow[t]{2}{*}{9} & & & & & 0.45 & 1,920 & 0.29 & 0.64 & 0.19 & 1,280 & 0.13 & 0.28 \\
\hline & & & & & $(0.08)$ & $(10 \%)$ & & & $(0.03)$ & $(7 \%)$ & & \\
\hline \multirow[t]{2}{*}{10} & & & & & 0.68 & 1,904 & 0.41 & 1.00 & 0.24 & 1,280 & 0.17 & 0.33 \\
\hline & & & & & $(0.14)$ & $(10 \%)$ & & & $(0.04)$ & $(7 \%)$ & & \\
\hline \multirow[t]{2}{*}{11} & & & & & & & & & 0.29 & 1,280 & 0.20 & 0.39 \\
\hline & & & & & & & & & $(0.05)$ & $(7 \%)$ & & \\
\hline \multirow[t]{2}{*}{12} & & & & & & & & & 0.35 & 1,280 & 0.23 & 0.48 \\
\hline & & & & & & & & & $(0.06)$ & $(7 \%)$ & & \\
\hline 13 & & & & & & & & & 0.42 & 1,280 & 0.29 & 0.58 \\
\hline & & & & & & & & & $(0.07)$ & $(7 \%)$ & & \\
\hline 14 & & & & & & & & & 0.53 & 1,280 & 0.35 & 0.73 \\
\hline & & & & & & & & & $(0.09)$ & $(7 \%)$ & & \\
\hline 15 & & & & & & & & & 0.74 & 1,264 & 0.49 & 1.00 \\
\hline & & & & & & & & & $(0.12)$ & $(7 \%)$ & & \\
\hline
\end{tabular}


Table 4. Estimating ranges: The table displays results for the dynamic ordered probit estimation. All firm data are collected from COMPUSTAT annual industrial database. We test three amounts of categories $(5,10$, and 15) under two different approaches of breaking the continuous measure of leverage (the market debt-equity ratio) into ranges we call ISW (intervals of the same width) and SNF (same number of firms). The sample consists of annual COMPUSTAT data from 1991 to 2006, excluding financial (SIC's 6000-6999) and regulated (SICs 4900-4999) firms. All capital structure determinants are normalized by assets, measured at time $t-1$ (unless noted otherwise), and are defined as follows: Firm size is firm sales in period $t$ divided by total sales in sample in period $t$; Volatility of cash flow is change in net income; Product uniqueness ratio of selling expenses to total sales; Asset tangibility assets attributable to property, plant and equipment; Depreciation and amortization; Growth and investment opportunities is a one period forward capital expenditure; Market-to-book ratio is total assets minus book equity plus market equity; Profitability is aftertax operating income, and Z-score is 3.3 times earnings before interest and taxes plus sales plus 1.4 times retained earnings plus 1.2 times working capital. The table also presents the estimated coefficients of the indicators of the lagged dependent variable and the cuts, or threshold values. The standard deviations are presented in parentheses below the corresponding estimate. Statistical significance at $1 \%, 5 \%$ and $10 \%$ levels is indicated by one, two and three asterisks, respectively.

\begin{tabular}{|c|c|c|c|c|c|c|}
\hline & \multicolumn{2}{|c|}{5 Ranges } & \multicolumn{2}{|c|}{10 Ranges } & \multicolumn{2}{|c|}{15 Ranges } \\
\hline & ISW & SNF & ISW & SNF & ISW & SNF \\
\hline \multirow[t]{2}{*}{ Firm Size } & 78.03 & 62.05 & 24.26 & 50.44 & 34.07 & 43.61 \\
\hline & $(63.70)$ & $(44.39)$ & $(47.29)$ & $(41.77)$ & $(43.85)$ & $(41.21)$ \\
\hline \multirow[t]{2}{*}{ Volatility of Cash Flow } & $-0.06^{*}$ & -0.02 & -0.02 & 0.00 & -0.01 & 0.00 \\
\hline & $(0.02)$ & $(0.02)$ & $(0.02)$ & $(0.01)$ & $(0.02)$ & $(0.01)$ \\
\hline \multirow[t]{2}{*}{ Product Uniqueness } & 0.00 & 0.00 & 0.00 & 0.00 & 0.00 & 0.00 \\
\hline & $(0.01)$ & $(0.00)$ & $(0.01)$ & $(0.00)$ & 0.00 & $(0.00)$ \\
\hline \multirow[t]{2}{*}{ Asset tangibility } & $-0.20^{*}$ & $-0.12^{*}$ & $-0.16^{*}$ & $-0.15^{*}$ & $-0.17^{*}$ & $-0.13^{*}$ \\
\hline & $(0.05)$ & $(0.03)$ & $(0.03)$ & $(0.03)$ & $(0.03)$ & $(0.03)$ \\
\hline \multirow[t]{2}{*}{ Depreciation and Amortization } & $-1.64^{*}$ & $-1.95^{*}$ & $-1.94^{*}$ & $-1.26^{*}$ & $-1.57^{*}$ & $-1.17^{*}$ \\
\hline & $(0.58)$ & $(0.46)$ & $(0.48)$ & $(0.34)$ & $(0.45)$ & $(0.34)$ \\
\hline \multirow[t]{2}{*}{ Growth/Inv Opportunities } & $-0.96^{*}$ & $-0.71^{*}$ & $-0.84^{*}$ & $-0.50^{*}$ & $-0.73^{*}$ & $-0.50^{*}$ \\
\hline & $(0.12)$ & $(0.09)$ & $(0.09)$ & $(0.07)$ & $(0.09)$ & $(0.07)$ \\
\hline \multirow[t]{2}{*}{ Mkt to book ratio } & $-0.02^{*}$ & -0.01 & -0.01 & 0.00 & 0.00 & 0.00 \\
\hline & $(0.01)$ & $(0.01)$ & $(0.01)$ & $(0.00)$ & $(0.01)$ & $(0.00)$ \\
\hline \multirow[t]{2}{*}{ Profitability } & -0.13 & $-0.10 * * *$ & $-0.12^{* * *}$ & -0.09 & -0.09 & -0.07 \\
\hline & $(0.08)$ & $(0.06)$ & $(0.06)$ & $(0.05)$ & $(0.06)$ & $(0.05)$ \\
\hline \multirow[t]{2}{*}{ Internal Reserves } & $-0.97^{*}$ & $-0.53^{*}$ & $-0.72^{*}$ & $-0.26^{* *}$ & $-0.56^{*}$ & $-0.18^{*}$ \\
\hline & $(0.15)$ & $(0.12)$ & $(0.13)$ & $(0.11)$ & $(0.12)$ & $(0.10)$ \\
\hline \multirow[t]{2}{*}{ Z-Score } & 0.00 & 0.00 & 0.00 & 0.00 & 0.00 & 0.00 \\
\hline & $(0.00)$ & $(0.00)$ & $(0.00)$ & $(0.00)$ & $(0.00)$ & $(0.00)$ \\
\hline
\end{tabular}


Table 4. Estimating ranges - Continued

\begin{tabular}{|c|c|c|c|c|c|c|}
\hline & \multicolumn{2}{|c|}{5 Ranges } & \multicolumn{2}{|c|}{10 Ranges } & \multicolumn{2}{|c|}{15 Ranges } \\
\hline & ISW & SNF & ISW & SNF & ISW & SNF \\
\hline \multirow[t]{2}{*}{ Lag Range 1} & $-2.98^{*}$ & $-2.88^{*}$ & $-4.61^{*}$ & $-4.41^{*}$ & $-5.13^{*}$ & $-5.00 *$ \\
\hline & $(0.06)$ & $(0.05)$ & $(0.10)$ & $(0.07)$ & $(0.12)$ & $(0.07)$ \\
\hline \multirow[t]{2}{*}{ Lag Range 2} & $-1.73^{*}$ & $-1.71^{*}$ & $-3.52^{*}$ & $-3.48^{*}$ & $-4.12^{*}$ & $-4.24^{*}$ \\
\hline & $(0.05)$ & $(0.04)$ & $(0.09)$ & $(0.06)$ & $(0.12)$ & $(0.08)$ \\
\hline \multirow[t]{2}{*}{ Lag Range 3} & $-0.84^{*}$ & $-0.88^{*}$ & $-2.89^{*}$ & $-2.96^{*}$ & $-3.55^{*}$ & $-3.94 *$ \\
\hline & $(0.05)$ & $(0.03)$ & $(0.09)$ & $(0.05)$ & $(0.12)$ & $(0.07)$ \\
\hline \multirow[t]{2}{*}{ Lag Range 4} & - & & $-2.35^{*}$ & $-2.43^{*}$ & $-3.14^{*}$ & $-3.50^{*}$ \\
\hline & & & $(0.09)$ & $(0.05)$ & $(0.12)$ & $(0.06)$ \\
\hline \multirow[t]{2}{*}{ Lag Range 5} & $0.92^{*}$ & $1.12^{*}$ & $-1.85^{*}$ & $-1.98^{*}$ & $-2.75^{*}$ & $-3.18^{*}$ \\
\hline & $(0.08)$ & $(0.04)$ & $(0.09)$ & $(0.05)$ & $(0.12)$ & $(0.06)$ \\
\hline \multirow[t]{2}{*}{ Lag Range 6} & & & $-1.42^{*}$ & $-1.54^{*}$ & $-2.39 *$ & $-2.80 *$ \\
\hline & & & $(0.09)$ & $(0.04)$ & $(0.12)$ & $(0.06)$ \\
\hline \multirow[t]{2}{*}{ Lag Range 7} & & & $-0.91^{*}$ & $-1.11^{*}$ & $-2.08^{*}$ & $-2.49^{*}$ \\
\hline & & & $(0.09)$ & $(0.04)$ & $(0.12)$ & $(0.06)$ \\
\hline \multirow[t]{2}{*}{ Lag Range 8} & & & $-0.51^{*}$ & $-0.55^{*}$ & $-1.70 *$ & $-2.22^{*}$ \\
\hline & & & $(0.10)$ & $(0.04)$ & $(0.12)$ & $(0.05)$ \\
\hline \multirow[t]{2}{*}{ Lag Range 9} & & & - & & $-1.51^{*}$ & $-1.87^{*}$ \\
\hline & & & & & $(0.12)$ & $(0.05)$ \\
\hline \multirow[t]{2}{*}{ Lag Range 10} & & & $0.57^{*}$ & $0.97^{*}$ & $-1.06^{*}$ & $-1.61^{*}$ \\
\hline & & & $(0.13)$ & $(0.05)$ & $(0.12)$ & $(0.05)$ \\
\hline \multirow[t]{2}{*}{ Lag Range 11} & & & & & $-0.89^{*}$ & $-1.25^{*}$ \\
\hline & & & & & $(0.12)$ & $(0.05)$ \\
\hline \multirow[t]{2}{*}{ Lag Range 12} & & & & & $-0.55^{*}$ & $-0.90^{*}$ \\
\hline & & & & & $(0.13)$ & $(0.05)$ \\
\hline \multirow[t]{2}{*}{ Lag Range 13} & & & & & -0.18 & $-0.52^{*}$ \\
\hline & & & & & $(0.14)$ & $(0.05)$ \\
\hline Lag Range 14 & & & & & - & \\
\hline \multirow[t]{2}{*}{ Lag Range 15} & & & & & $0.82^{*}$ & $0.88^{*}$ \\
\hline & & & & & $(0.17)$ & $(0.05)$ \\
\hline
\end{tabular}


Table 4. Estimating ranges - Continued

\begin{tabular}{|c|c|c|c|c|c|c|}
\hline & \multicolumn{2}{|c|}{5 Ranges } & \multicolumn{2}{|c|}{10 Ranges } & \multicolumn{2}{|c|}{15 Ranges } \\
\hline & ISW & SNF & ISW & SNF & ISW & SNF \\
\hline \multirow[t]{2}{*}{ Cut 1} & $-3.16^{*}$ & $-3.41^{*}$ & $-4.88^{*}$ & $-5.03^{*}$ & $-5.36^{*}$ & $-5.86^{*}$ \\
\hline & $(0.13)$ & $(0.11)$ & $(0.14)$ & $(0.10)$ & $(0.16)$ & $(0.10)$ \\
\hline \multirow[t]{2}{*}{ Cut 2} & $-1.69^{*}$ & $-2.05^{*}$ & $-3.84^{*}$ & $-4.26^{*}$ & $-4.51^{*}$ & $-5.29^{*}$ \\
\hline & $(0.13)$ & $(0.10)$ & $(0.14)$ & $(0.10)$ & $(0.16)$ & $(0.10)$ \\
\hline \multirow[t]{2}{*}{ Cut 3} & $-0.52^{*}$ & $-0.89^{*}$ & $-3.02^{*}$ & $-3.51^{*}$ & $-3.85^{*}$ & $-4.68^{*}$ \\
\hline & $(0.13)$ & $(0.10)$ & $(0.14)$ & $(0.10)$ & $(0.16)$ & $(0.10)$ \\
\hline \multirow[t]{2}{*}{ Cut 4} & $0.68^{*}$ & $0.37 *$ & $-2.33^{*}$ & $-2.88^{*}$ & $-3.27^{*}$ & $-4.16^{*}$ \\
\hline & $(0.13)$ & $(0.10)$ & $(0.14)$ & $(0.09)$ & $(0.16)$ & $(0.10)$ \\
\hline \multirow[t]{2}{*}{ Cut 5} & & & $-1.72^{*}$ & $-2.29^{*}$ & $-2.79^{*}$ & $-3.71^{*}$ \\
\hline & & & $(0.14)$ & (0.09) & $(0.16)$ & $(0.10)$ \\
\hline \multirow[t]{2}{*}{ Cut 6} & & & $-1.15^{*}$ & $-1.72^{*}$ & $-2.34^{*}$ & $-3.30^{*}$ \\
\hline & & & $(0.14)$ & $(0.09)$ & $(0.16)$ & $(0.09)$ \\
\hline \multirow[t]{2}{*}{ Cut 7} & & & $-0.55^{*}$ & $-1.12^{*}$ & $-1.93^{*}$ & $-2.90^{*}$ \\
\hline & & & $(0.14)$ & $(0.09)$ & $(0.16)$ & $(0.09)$ \\
\hline \multirow[t]{2}{*}{ Cut 8} & & & 0.07 & $-0.43^{*}$ & $-1.54^{*}$ & $-2.52^{*}$ \\
\hline & & & $(0.14)$ & $(0.09)$ & $(0.16)$ & $(0.09)$ \\
\hline \multirow[t]{2}{*}{ Cut 9} & & & $0.76^{*}$ & $0.48^{*}$ & $-1.16^{*}$ & $-2.14^{*}$ \\
\hline & & & $(0.15)$ & $(0.09)$ & $(0.16)$ & $(0.09)$ \\
\hline \multirow[t]{2}{*}{ Cut 10} & & & & & $-0.77^{*}$ & $-1.74^{*}$ \\
\hline & & & & & $(0.16)$ & $(0.09)$ \\
\hline \multirow[t]{2}{*}{ Cut 11} & & & & & $-0.34^{* *}$ & $-1.33^{*}$ \\
\hline & & & & & $(0.16)$ & $(0.09)$ \\
\hline \multirow[t]{2}{*}{ Cut 12} & & & & & 0.05 & $-0.85^{*}$ \\
\hline & & & & & $(0.16)$ & $(0.09)$ \\
\hline \multirow[t]{2}{*}{ Cut 13} & & & & & $0.49^{*}$ & $-0.29^{*}$ \\
\hline & & & & & $(0.16)$ & $(0.09)$ \\
\hline \multirow[t]{2}{*}{ Cut 14} & & & & & $1.07^{*}$ & $0.52^{*}$ \\
\hline & & & & & $(0.17)$ & $(0.09)$ \\
\hline Log Likelihood & -10289.10 & -14897.72 & -17829.11 & -23755.686 & -22749.67 & -29479.599 \\
\hline LR chi2 & 5733.39 & 7819.83 & 8109.36 & 9595.37 & 9042.47 & 10104.45 \\
\hline Prob $>$ chi2 & 0.00 & 0.00 & 0.00 & 0.00 & 0.00 & 0.00 \\
\hline $\begin{array}{c}\text { McFadden's } \\
\text { Adjusted Pseudo R2 }\end{array}$ & 0.22 & 0.21 & 0.18 & 0.17 & 0.16 & 0.14 \\
\hline
\end{tabular}




\section{Table 5. Predicted probabilities}

The table displays the predicted probabilities the models with 5, 10, and 15 categories when data is broken under both the ISW and SNF criteria. The probabilities are calculated by averaging the predicted individual probabilities of firms in each range, which are found by using the coefficients estimated by the dynamic ordered probit procedure. The highest probability is indicated by one asterisk.

\begin{tabular}{|c|c|c|c|c|c|c|}
\hline \multirow[b]{3}{*}{$\begin{array}{l}\text { Probability of } \\
\text { being in range }\end{array}$} & \multicolumn{6}{|c|}{ Categories in the model } \\
\hline & \multicolumn{2}{|c|}{5 Ranges } & \multicolumn{2}{|c|}{10 Ranges } & \multicolumn{2}{|c|}{15 Ranges } \\
\hline & ISW & SNF & ISW & $\mathrm{SNF}$ & ISW & $\mathrm{SNF}$ \\
\hline 1 & $0.58^{*}$ & 0.17 & $0.38^{*}$ & 0.10 & $0.31^{*}$ & 0.07 \\
\hline 2 & 0.25 & 0.21 & 0.20 & 0.08 & 0.15 & 0.05 \\
\hline 3 & 0.11 & $0.22^{*}$ & 0.14 & 0.10 & 0.12 & 0.07 \\
\hline 4 & 0.05 & 0.22 & 0.10 & 0.11 & 0.10 & 0.07 \\
\hline 5 & 0.01 & 0.18 & 0.07 & $0.11^{*}$ & 0.08 & 0.07 \\
\hline 6 & & & 0.05 & 0.11 & 0.06 & 0.07 \\
\hline 7 & & & 0.03 & 0.11 & 0.05 & $0.07^{*}$ \\
\hline 8 & & & 0.02 & 0.11 & 0.04 & 0.07 \\
\hline 9 & & & 0.01 & 0.10 & 0.03 & 0.07 \\
\hline 10 & & & 0.00 & 0.09 & 0.02 & 0.07 \\
\hline 11 & & & & & 0.02 & 0.07 \\
\hline 12 & & & & & 0.01 & 0.07 \\
\hline 13 & & & & & 0.01 & 0.07 \\
\hline 14 & & & & & 0.00 & 0.07 \\
\hline 15 & & & & & 0.00 & 0.06 \\
\hline
\end{tabular}




\section{Table 6. Directions of the partial effects}

The figure presents both the predicted and the estimated directions of the partial effects of the capital structure determinants. The shaded cells mean that the covariate is one-percent significant. (+) means that the effect is positively related with leverage, (-) means that the effect is negatively related with leverage. (?) means that the predicted impact varies according to the model.

\begin{tabular}{|c|c|c|c|c|c|c|c|c|c|}
\hline & \multicolumn{4}{|c|}{ ISW } & \multicolumn{3}{|c|}{ SNF } & \multirow[b]{2}{*}{ Random Effects } & \multirow[b]{2}{*}{ Fixed Effects } \\
\hline & Predicted & 5 & 10 & 15 & 5 & 10 & 15 & & \\
\hline Firm size & $?$ & + & + & + & + & + & + & + & + \\
\hline Volatility of cash flow & - & - & - & - & - & - & - & - & - \\
\hline Product uniqueness & - & - & - & - & - & - & - & - & - \\
\hline Asset tangibility & + & - & - & - & - & - & - & + & - \\
\hline Depreciation and amortization & + & - & - & - & - & - & - & - & - \\
\hline Growth and invest. opportunities & - & - & - & - & - & - & - & - & - \\
\hline Market-to-book ratio & - & - & - & - & - & + & + & - & - \\
\hline Profitability & ? & - & - & - & - & - & - & + & + \\
\hline Internal reserves & - & - & - & - & - & - & - & - & - \\
\hline Altman's Z-score & + & - & - & - & - & + & + & - & - \\
\hline
\end{tabular}


Table 7. Marginal effects of a unit change in capital structure determinants when ranges are coded under

the ISW criterion: This table displays the average partial effects for a one unit change in each of the capital structure determinants (continuous variables) considered in this paper. We evaluate the predicted outcomes for each firm relative to the estimated cut points in the normal distribution function and average these values obtaining the relative contribution of each variable to the probability (normalized to range from 0 to 100 ) of remaining in each of the ranges.

\begin{tabular}{|c|c|c|c|c|c|c|c|c|c|c|c|c|c|c|c|c|}
\hline & & Range 1 & Range 2 & Range 3 & Range 4 & Range 5 & Range 6 & Range 7 & Range 8 & Range 9 & Range 10 & Range 11 & Range 12 & Range 13 & Range 14 & Range 15 \\
\hline \multirow{3}{*}{ Firm Size } & 5 Cat & -1600.44 & 599.61 & 503.12 & 341.14 & 156.57 & & & & & & & & & & \\
\hline & 10Cat & -469.60 & 19.90 & 59.80 & 82.44 & 80.55 & 71.05 & 60.66 & 44.65 & 29.84 & 20.71 & & & & & \\
\hline & $15 \mathrm{Cat}$ & -592.63 & -35.25 & 5.02 & 44.62 & 65.87 & 78.01 & 76.38 & 70.46 & 65.66 & 58.20 & 54.07 & 37.08 & 30.25 & 23.87 & 18.40 \\
\hline \multirow{3}{*}{$\begin{array}{l}\text { Volatility of } \\
\text { Cash Flow }\end{array}$} & 5 Cat & 1.22 & -0.46 & -0.38 & -0.26 & -0.12 & & & & & & & & & & \\
\hline & 10Cat & 0.43 & -0.02 & -0.05 & -0.08 & -0.07 & -0.06 & -0.06 & -0.04 & -0.03 & -0.02 & & & & & \\
\hline & 15Cat & 0.26 & 0.02 & 0.00 & -0.02 & -0.03 & -0.03 & -0.03 & -0.03 & -0.03 & -0.03 & -0.02 & -0.02 & -0.01 & -0.01 & -0.01 \\
\hline \multirow{3}{*}{$\begin{array}{l}\text { Product } \\
\text { Uniqueness }\end{array}$} & 5 Cat & 0.03 & -0.01 & -0.01 & -0.01 & 0.00 & & & & & & & & & & \\
\hline & 10Cat & 0.05 & 0.00 & -0.01 & -0.01 & -0.01 & -0.01 & -0.01 & 0.00 & 0.00 & 0.00 & & & & & \\
\hline & $15 \mathrm{Cat}$ & 0.00 & 0.00 & 0.00 & 0.00 & 0.00 & 0.00 & 0.00 & 0.00 & 0.00 & 0.00 & 0.00 & 0.00 & 0.00 & 0.00 & 0.00 \\
\hline \multirow{3}{*}{$\begin{array}{c}\text { Asset } \\
\text { tangibility }\end{array}$} & 5 Cat & 4.16 & -1.56 & -1.31 & -0.89 & -0.41 & & & & & & & & & & \\
\hline & 10Cat & 3.17 & -0.13 & -0.40 & -0.56 & -0.54 & -0.48 & -0.41 & -0.30 & -0.20 & -0.14 & & & & & \\
\hline & $15 \mathrm{Cat}$ & 3.00 & 0.18 & -0.03 & -0.23 & -0.33 & -0.39 & -0.39 & -0.36 & -0.33 & -0.29 & -0.27 & -0.19 & -0.15 & -0.12 & -0.09 \\
\hline \multirow{2}{*}{$\begin{array}{l}\text { Depreciation } \\
\text { and }\end{array}$} & 5 Cat & 33.68 & -12.62 & -10.59 & -7.18 & -3.29 & & & & & & & & & & \\
\hline & 10Cat & 37.46 & -1.59 & -4.77 & -6.58 & -6.43 & -5.67 & -4.84 & -3.56 & -2.38 & -1.65 & & & & & \\
\hline Amortization & $15 \mathrm{Cat}$ & 27.36 & 1.63 & -0.23 & -2.06 & -3.04 & -3.60 & -3.53 & -3.25 & -3.03 & -2.69 & -2.50 & -1.71 & -1.40 & -1.10 & -0.85 \\
\hline \multirow{3}{*}{$\begin{array}{l}\text { Growth/Inv } \\
\text { Opportunities }\end{array}$} & 5 Cat & 19.63 & -7.36 & -6.17 & -4.19 & -1.92 & & & & & & & & & & \\
\hline & $10 \mathrm{Cat}$ & 16.26 & -0.69 & -2.07 & -2.85 & -2.79 & -2.46 & -2.10 & -1.55 & -1.03 & -0.72 & & & & & \\
\hline & 15Cat & 12.66 & 0.75 & -0.11 & -0.95 & -1.41 & -1.67 & -1.63 & -1.51 & -1.40 & -1.24 & -1.16 & -0.79 & -0.65 & -0.51 & -0.39 \\
\hline \multirow{3}{*}{$\begin{array}{l}\text { Mkt to book } \\
\text { Ratio }\end{array}$} & 5 Cat & 0.45 & -0.17 & -0.14 & -0.10 & -0.04 & & & & & & & & & & \\
\hline & 10Cat & 0.11 & 0.00 & -0.01 & -0.02 & -0.02 & -0.02 & -0.01 & -0.01 & -0.01 & -0.01 & & & & & \\
\hline & $15 \mathrm{Cat}$ & 0.04 & 0.00 & 0.00 & 0.00 & 0.00 & -0.01 & -0.01 & -0.01 & 0.00 & 0.00 & 0.00 & 0.00 & 0.00 & 0.00 & 0.00 \\
\hline
\end{tabular}


Table 7. Marginal effects of a unit change in capital structure determinants when ranges are coded under the ISW criterion - Continued

\begin{tabular}{|c|c|c|c|c|c|c|c|c|c|c|c|c|c|c|c|c|}
\hline & & Range 1 & Range 2 & Range 3 & Range 4 & Range 5 & Range 6 & Range 7 & Range 8 & Range 9 & Range 10 & Range 11 & Range 12 & Range 13 & Range 14 & Range 15 \\
\hline \multirow{3}{*}{ Profitability } & 5 Cat & 2.71 & -1.02 & -0.85 & -0.58 & -0.27 & & & & & & & & & & \\
\hline & 10Cat & 2.37 & -0.10 & -0.30 & -0.42 & -0.41 & -0.36 & -0.31 & -0.23 & -0.15 & -0.10 & & & & & \\
\hline & 15Cat & 1.57 & 0.09 & -0.01 & -0.12 & -0.17 & -0.21 & -0.20 & -0.19 & -0.17 & -0.15 & -0.14 & -0.10 & -0.08 & -0.06 & -0.05 \\
\hline \multirow{3}{*}{$\begin{array}{l}\text { Internal } \\
\text { Reserves }\end{array}$} & 5Cat & 19.94 & -7.47 & -6.27 & -4.25 & -1.95 & & & & & & & & & & \\
\hline & 10Cat & 13.93 & -0.59 & -1.77 & -2.45 & -2.39 & -2.11 & -1.80 & -1.32 & -0.89 & -0.61 & & & & & \\
\hline & 15Cat & 9.66 & 0.57 & -0.08 & -0.73 & -1.07 & -1.27 & -1.25 & -1.15 & -1.07 & -0.95 & -0.88 & -0.60 & -0.49 & -0.39 & -0.30 \\
\hline \multirow{3}{*}{ Z-Score } & 5 Cat & 0.00 & 0.00 & 0.00 & 0.00 & 0.00 & & & & & & & & & & \\
\hline & 10Cat & 0.00 & 0.00 & 0.00 & 0.00 & 0.00 & 0.00 & 0.00 & 0.00 & 0.00 & 0.00 & & & & & \\
\hline & $15 \mathrm{Cat}$ & 0.00 & 0.00 & 0.00 & 0.00 & 0.00 & 0.00 & 0.00 & 0.00 & 0.00 & 0.00 & 0.00 & 0.00 & 0.00 & 0.00 & 0.00 \\
\hline
\end{tabular}




\section{Table 8. Marginal effects of a standard deviation change in capital structure determinants when ranges}

are coded under the ISW criterion: This table displays the average partial effects for a one standard deviation change in each of the capital structure determinants (continuous variables) considered in this paper. We evaluate the predicted outcomes for each firm relative to the estimated cut points in the normal distribution function and average these values obtaining the relative contribution of each variable to the probability (normalized to range from 0 to 100) of remaining in each of the ranges.

\begin{tabular}{|c|c|c|c|c|c|c|c|c|c|c|c|c|c|c|c|c|}
\hline & & Range 1 & Range 2 & Range 3 & Range 4 & Range 5 & Range 6 & Range 7 & Range 8 & Range 9 & Range 10 & Range 11 & Range 12 & Range 13 & Range 14 & Range 15 \\
\hline \multirow{3}{*}{ Firm Size } & 5Cat & -1.40 & 0.52 & 0.44 & 0.30 & 0.14 & & & & & & & & & & \\
\hline & 10Cat & -0.41 & 0.02 & 0.05 & 0.07 & 0.07 & 0.06 & 0.05 & 0.04 & 0.03 & 0.02 & & & & & \\
\hline & 15Cat & -0.52 & -0.03 & 0.00 & 0.04 & 0.06 & 0.07 & 0.07 & 0.06 & 0.06 & 0.05 & 0.05 & 0.03 & 0.03 & 0.02 & 0.02 \\
\hline \multirow{3}{*}{$\begin{array}{l}\text { Volatility of } \\
\text { Cash Flow }\end{array}$} & 5Cat & 6.96 & -2.61 & -2.19 & -1.48 & -0.68 & & & & & & & & & & \\
\hline & 10Cat & 2.45 & -0.10 & -0.31 & -0.43 & -0.42 & -0.37 & -0.32 & -0.23 & -0.16 & -0.11 & & & & & \\
\hline & 15Cat & 1.47 & 0.09 & -0.01 & -0.11 & -0.16 & -0.19 & -0.19 & -0.17 & -0.16 & -0.14 & -0.13 & -0.09 & -0.07 & -0.06 & -0.05 \\
\hline \multirow{3}{*}{$\begin{array}{c}\text { Product } \\
\text { Uniqueness }\end{array}$} & 5 Cat & 0.75 & -0.28 & -0.24 & -0.16 & -0.07 & & & & & & & & & & \\
\hline & 10Cat & 1.41 & -0.06 & -0.18 & -0.25 & -0.24 & -0.21 & -0.18 & -0.13 & -0.09 & -0.06 & & & & & \\
\hline & 15 Cat & -0.05 & 0.00 & 0.00 & 0.00 & 0.01 & 0.01 & 0.01 & 0.01 & 0.01 & 0.00 & 0.00 & 0.00 & 0.00 & 0.00 & 0.00 \\
\hline \multirow{3}{*}{$\begin{array}{c}\text { Asset } \\
\text { tangibility }\end{array}$} & 5 Cat & 36.22 & -13.57 & -11.39 & -7.72 & -3.54 & & & & & & & & & & \\
\hline & 10Cat & 27.58 & -1.17 & -3.51 & -4.84 & -4.73 & -4.17 & -3.56 & -2.62 & -1.75 & -1.22 & & & & & \\
\hline & $15 \mathrm{Cat}$ & 26.13 & 1.55 & -0.22 & -1.97 & -2.90 & -3.44 & -3.37 & -3.11 & -2.89 & -2.57 & -2.38 & -1.63 & -1.33 & -1.05 & -0.81 \\
\hline Depreciation & 5 Cat & 2.62 & -0.98 & -0.82 & -0.56 & -0.26 & & & & & & & & & & \\
\hline and & 10Cat & 2.91 & -0.12 & -0.37 & -0.51 & -0.50 & -0.44 & -0.38 & -0.28 & -0.19 & -0.13 & & & & & \\
\hline Amortization & $15 \mathrm{Cat}$ & 2.13 & 0.13 & -0.02 & -0.16 & -0.24 & -0.28 & -0.27 & -0.25 & -0.24 & -0.21 & -0.19 & -0.13 & -0.11 & -0.09 & -0.07 \\
\hline \multirow{3}{*}{$\begin{array}{l}\text { Growth/Inv } \\
\text { Opportunities }\end{array}$} & 5 Cat & 150.88 & -56.53 & -47.43 & -32.16 & -14.76 & & & & & & & & & & \\
\hline & 10Cat & 124.92 & -5.29 & -15.91 & -21.93 & -21.43 & -18.90 & -16.13 & -11.88 & -7.94 & -5.51 & & & & & \\
\hline & 15 Cat & 97.28 & 5.79 & -0.82 & -7.32 & -10.81 & -12.81 & -12.54 & -11.57 & -10.78 & -9.55 & -8.88 & -6.09 & -4.97 & -3.92 & -3.02 \\
\hline \multirow{3}{*}{$\begin{array}{l}\text { Mkt to book } \\
\text { ratio }\end{array}$} & 5 Cat & 2.47 & -0.93 & -0.78 & -0.53 & -0.24 & & & & & & & & & & \\
\hline & 10Cat & 0.63 & -0.03 & -0.08 & -0.11 & -0.11 & -0.09 & -0.08 & -0.06 & -0.04 & -0.03 & & & & & \\
\hline & $15 \mathrm{Cat}$ & 0.24 & 0.01 & 0.00 & -0.02 & -0.03 & -0.03 & -0.03 & -0.03 & -0.03 & -0.02 & -0.02 & -0.01 & -0.01 & -0.01 & -0.01 \\
\hline
\end{tabular}


Table 8. Marginal effects of a standard deviation change in capital structure determinants when ranges are coded under the ISW criterion - Continued

\begin{tabular}{|c|c|c|c|c|c|c|c|c|c|c|c|c|c|c|c|c|}
\hline & & Range 1 & Range 2 & Range 3 & Range 4 & Range 5 & Range 6 & Range 7 & Range 8 & Range 9 & Range 10 & Range 11 & Range 12 & Range 13 & Range 14 & Range 15 \\
\hline \multirow{3}{*}{ Profitability } & 5Cat & 3.81 & -1.43 & -1.20 & -0.81 & -0.37 & & & & & & & & & & \\
\hline & 10Cat & 3.32 & -0.14 & -0.42 & -0.58 & -0.57 & -0.50 & -0.43 & -0.32 & -0.21 & -0.15 & & & & & \\
\hline & $15 \mathrm{Cat}$ & 2.20 & 0.13 & -0.02 & -0.17 & -0.24 & -0.29 & -0.28 & -0.26 & -0.24 & -0.22 & -0.20 & -0.14 & -0.11 & -0.09 & -0.07 \\
\hline \multirow{3}{*}{$\begin{array}{l}\text { Internal } \\
\text { Reserves }\end{array}$} & 5 Cat & 3.61 & -1.35 & -1.13 & -0.77 & -0.35 & & & & & & & & & & \\
\hline & 10Cat & 2.52 & -0.11 & -0.32 & -0.44 & -0.43 & -0.38 & -0.33 & -0.24 & -0.16 & -0.11 & & & & & \\
\hline & 15Cat & 1.75 & 0.10 & -0.01 & -0.13 & -0.19 & -0.23 & -0.23 & -0.21 & -0.19 & -0.17 & -0.16 & -0.11 & -0.09 & -0.07 & -0.05 \\
\hline \multirow{3}{*}{ Z-Score } & 5Cat & 0.67 & -0.25 & -0.21 & -0.14 & -0.07 & & & & & & & & & & \\
\hline & 10Cat & 0.32 & -0.01 & -0.04 & -0.06 & -0.05 & -0.05 & -0.04 & -0.03 & -0.02 & -0.01 & & & & & \\
\hline & $15 \mathrm{Cat}$ & -0.02 & 0.00 & 0.00 & 0.00 & 0.00 & 0.00 & 0.00 & 0.00 & 0.00 & 0.00 & 0.00 & 0.00 & 0.00 & 0.00 & 0.00 \\
\hline
\end{tabular}


Table 9. Marginal effects of a unit change in capital structure determinants when ranges are coded under

the SNF criterion: This table displays the average partial effects for a one unit change in each of the capital structure determinants (continuous variables) considered in this paper. We evaluate the predicted outcomes for each firm relative to the estimated cut points in the normal distribution function and average these values obtaining the relative contribution of each variable to the probability (normalized to range from 0 to 100) of remaining in each of the ranges.

\begin{tabular}{|c|c|c|c|c|c|c|c|c|c|c|c|c|c|c|c|c|}
\hline & & Range 1 & Range 2 & Range 3 & Range 4 & Range 5 & Range 6 & Range 7 & Range 8 & Range 9 & Range 10 & Range 11 & Range 12 & Range 13 & Range 14 & Range 15 \\
\hline \multirow{3}{*}{ Firm Size } & 5 Cat & -776.26 & -334.43 & -53.57 & 253.85 & 910.41 & & & & & & & & & & \\
\hline & 10Cat & -428.53 & -172.72 & -174.88 & -115.17 & -49.25 & 18.62 & 83.20 & 152.43 & 240.30 & 446.01 & & & & & \\
\hline & $15 \mathrm{Cat}$ & -293.16 & -110.55 & -125.23 & -104.33 & -79.80 & -56.25 & -32.69 & -8.20 & 15.81 & 40.40 & 66.20 & 98.04 & 130.30 & 184.69 & 274.77 \\
\hline \multirow{3}{*}{$\begin{array}{l}\text { Volatility of } \\
\text { Cash Flow }\end{array}$} & 5 Cat & 0.20 & 0.09 & 0.01 & -0.07 & -0.24 & & & & & & & & & & \\
\hline & $10 \mathrm{Cat}$ & 0.03 & 0.01 & 0.01 & 0.01 & 0.00 & 0.00 & -0.01 & -0.01 & -0.02 & -0.03 & & & & & \\
\hline & 15 Cat & 0.00 & 0.00 & 0.00 & 0.00 & 0.00 & 0.00 & 0.00 & 0.00 & 0.00 & 0.00 & 0.00 & 0.00 & 0.00 & 0.00 & 0.00 \\
\hline \multirow{3}{*}{$\begin{array}{l}\text { Product } \\
\text { Uniqueness }\end{array}$} & 5 Cat & 0.00 & 0.00 & 0.00 & 0.00 & 0.00 & & & & & & & & & & \\
\hline & $10 \mathrm{Cat}$ & 0.00 & 0.00 & 0.00 & 0.00 & 0.00 & 0.00 & 0.00 & 0.00 & 0.00 & 0.00 & & & & & \\
\hline & 15 Cat & 0.00 & 0.00 & 0.00 & 0.00 & 0.00 & 0.00 & 0.00 & 0.00 & 0.00 & 0.00 & 0.00 & 0.00 & 0.00 & 0.00 & 0.00 \\
\hline \multirow{3}{*}{$\begin{array}{c}\text { Asset } \\
\text { tangibility }\end{array}$} & 5 Cat & 1.54 & 0.66 & 0.11 & -0.50 & -1.80 & & & & & & & & & & \\
\hline & 10Cat & 1.26 & 0.51 & 0.52 & 0.34 & 0.15 & -0.05 & -0.25 & -0.45 & -0.71 & -1.31 & & & & & \\
\hline & $15 \mathrm{Cat}$ & 0.90 & 0.34 & 0.39 & 0.32 & 0.25 & 0.17 & 0.10 & 0.03 & -0.05 & -0.12 & -0.20 & -0.30 & -0.40 & -0.57 & -0.85 \\
\hline \multirow{3}{*}{$\begin{array}{l}\text { Depreciation } \\
\text { and } \\
\text { Amortization }\end{array}$} & 5 Cat & 24.38 & 10.50 & 1.68 & -7.97 & -28.59 & & & & & & & & & & \\
\hline & 10Cat & 10.70 & 4.31 & 4.37 & 2.88 & 1.23 & -0.47 & -2.08 & -3.81 & -6.00 & -11.14 & & & & & \\
\hline & $15 \mathrm{Cat}$ & 7.86 & 2.96 & 3.36 & 2.80 & 2.14 & 1.51 & 0.88 & 0.22 & -0.42 & -1.08 & -1.77 & -2.63 & -3.49 & -4.95 & -7.37 \\
\hline \multirow{3}{*}{$\begin{array}{l}\text { Growth/Inv } \\
\text { Opportunities }\end{array}$} & 5 Cat & 8.88 & 3.82 & 0.61 & -2.90 & -10.41 & & & & & & & & & & \\
\hline & $10 \mathrm{Cat}$ & 4.22 & 1.70 & 1.72 & 1.13 & 0.49 & -0.18 & -0.82 & -1.50 & -2.37 & -4.39 & & & & & \\
\hline & $15 \mathrm{Cat}$ & 3.37 & 1.27 & 1.44 & 1.20 & 0.92 & 0.65 & 0.38 & 0.09 & -0.18 & -0.46 & -0.76 & -1.13 & -1.50 & -2.12 & -3.16 \\
\hline \multirow{3}{*}{$\begin{array}{c}\text { Mkt to book } \\
\text { Ratio }\end{array}$} & 5 Cat & 0.07 & 0.03 & 0.00 & -0.02 & -0.08 & & & & & & & & & & \\
\hline & $10 \mathrm{Cat}$ & -0.02 & -0.01 & -0.01 & -0.01 & 0.00 & 0.00 & 0.00 & 0.01 & 0.01 & 0.02 & & & & & \\
\hline & $15 \mathrm{Cat}$ & -0.01 & -0.01 & -0.01 & 0.00 & 0.00 & 0.00 & 0.00 & 0.00 & 0.00 & 0.00 & 0.00 & 0.00 & 0.01 & 0.01 & 0.01 \\
\hline
\end{tabular}


Table 9. Marginal effects of a unit change in capital structure determinants when ranges are coded under the SNF criterion - Continued

\begin{tabular}{|c|c|c|c|c|c|c|c|c|c|c|c|c|c|c|c|c|}
\hline & & Range 1 & Range 2 & Range 3 & Range 4 & Range 5 & Range 6 & Range 7 & Range 8 & Range 9 & Range 10 & Range 11 & Range 12 & Range 13 & Range 14 & Range 15 \\
\hline \multirow{3}{*}{ Profitability } & 5 Cat & 1.30 & 0.56 & 0.09 & -0.43 & -1.53 & & & & & & & & & & \\
\hline & 10Cat & 0.74 & 0.30 & 0.30 & 0.20 & 0.08 & -0.03 & -0.14 & -0.26 & -0.41 & -0.77 & & & & & \\
\hline & $15 \mathrm{Cat}$ & 0.48 & 0.18 & 0.21 & 0.17 & 0.13 & 0.09 & 0.05 & 0.01 & -0.03 & -0.07 & -0.11 & -0.16 & -0.21 & -0.30 & -0.45 \\
\hline \multirow{3}{*}{$\begin{array}{l}\text { Internal } \\
\text { Reserves }\end{array}$} & 5 Cat & 6.63 & 2.86 & 0.46 & -2.17 & -7.77 & & & & & & & & & & \\
\hline & 10Cat & 2.17 & 0.88 & 0.89 & 0.58 & 0.25 & -0.09 & -0.42 & -0.77 & -1.22 & -2.26 & & & & & \\
\hline & $15 \mathrm{Cat}$ & 1.21 & 0.46 & 0.52 & 0.43 & 0.33 & 0.23 & 0.13 & 0.03 & -0.07 & -0.17 & -0.27 & -0.40 & -0.54 & -0.76 & -1.13 \\
\hline \multirow{3}{*}{ Z-Score } & 5 Cat & 0.01 & 0.00 & 0.00 & 0.00 & -0.01 & & & & & & & & & & \\
\hline & 10Cat & -0.01 & 0.00 & 0.00 & 0.00 & 0.00 & 0.00 & 0.00 & 0.00 & 0.01 & 0.01 & & & & & \\
\hline & 15 Cat & -0.01 & 0.00 & 0.00 & 0.00 & 0.00 & 0.00 & 0.00 & 0.00 & 0.00 & 0.00 & 0.00 & 0.00 & 0.00 & 0.00 & 0.01 \\
\hline
\end{tabular}


Table 10. Marginal effects of a standard deviation change in capital structure determinants when ranges are coded under

the SNF criterion: This table displays the average partial effects for a one standard deviation change in each of the capital structure determinants (continuous variables) considered in this paper. We evaluate the predicted outcomes for each firm relative to the estimated cut points in the normal distribution function and average these values obtaining the relative contribution of each variable to the probability (normalized to range from 0 to 100) of remaining in each of the ranges.

\begin{tabular}{|c|c|c|c|c|c|c|c|c|c|c|c|c|c|c|c|c|}
\hline & & Range 1 & Range 2 & Range 3 & Range 4 & Range 5 & Range 6 & Range 7 & Range 8 & Range 9 & Range 10 & Range 11 & Range 12 & Range 13 & Range 14 & Range 15 \\
\hline \multirow{3}{*}{ Firm Size } & 5 Cat & -0.68 & -0.29 & -0.05 & 0.22 & 0.80 & & & & & & & & & & \\
\hline & 10Cat & -0.37 & -0.15 & -0.15 & -0.10 & -0.04 & 0.02 & 0.07 & 0.13 & 0.21 & 0.39 & & & & & \\
\hline & 15 Cat & -0.26 & -0.10 & -0.11 & -0.09 & -0.07 & -0.05 & -0.03 & -0.01 & 0.01 & 0.04 & 0.06 & 0.09 & 0.11 & 0.16 & 0.24 \\
\hline \multirow{3}{*}{$\begin{array}{l}\text { Volatility of } \\
\text { Cash Flow }\end{array}$} & 5 Cat & 1.17 & 0.50 & 0.08 & -0.38 & -1.37 & & & & & & & & & & \\
\hline & 10Cat & 0.15 & 0.06 & 0.06 & 0.04 & 0.02 & -0.01 & -0.03 & -0.05 & -0.09 & -0.16 & & & & & \\
\hline & $15 \mathrm{Cat}$ & 0.00 & 0.00 & 0.00 & 0.00 & 0.00 & 0.00 & 0.00 & 0.00 & 0.00 & 0.00 & 0.00 & 0.00 & 0.00 & 0.00 & 0.00 \\
\hline \multirow{3}{*}{$\begin{array}{c}\text { Product } \\
\text { Uniqueness }\end{array}$} & 5 Cat & 0.09 & 0.04 & 0.01 & -0.03 & -0.10 & & & & & & & & & & \\
\hline & 10Cat & 0.01 & 0.00 & 0.00 & 0.00 & 0.00 & 0.00 & 0.00 & 0.00 & 0.00 & -0.01 & & & & & \\
\hline & $15 \mathrm{Cat}$ & 0.00 & 0.00 & 0.00 & 0.00 & 0.00 & 0.00 & 0.00 & 0.00 & 0.00 & 0.00 & 0.00 & 0.00 & 0.00 & 0.00 & 0.00 \\
\hline \multirow{3}{*}{$\begin{array}{c}\text { Asset } \\
\text { tangibility }\end{array}$} & 5 Cat & 13.38 & 5.76 & 0.92 & -4.37 & -15.69 & & & & & & & & & & \\
\hline & 10Cat & 11.01 & 4.44 & 4.49 & 2.96 & 1.26 & -0.48 & -2.14 & -3.91 & -6.17 & -11.45 & & & & & \\
\hline & $15 \mathrm{Cat}$ & 7.86 & 2.96 & 3.36 & 2.80 & 2.14 & 1.51 & 0.88 & 0.22 & -0.42 & -1.08 & -1.77 & -2.63 & -3.49 & -4.95 & -7.37 \\
\hline Depreciation & 5 Cat & 1.89 & 0.82 & 0.13 & -0.62 & -2.22 & & & & & & & & & & \\
\hline and & 10Cat & 0.83 & 0.34 & 0.34 & 0.22 & 0.10 & -0.04 & -0.16 & -0.30 & -0.47 & -0.87 & & & & & \\
\hline Amortization & 15 Cat & 0.61 & 0.23 & 0.26 & 0.22 & 0.17 & 0.12 & 0.07 & 0.02 & -0.03 & -0.08 & -0.14 & -0.20 & -0.27 & -0.38 & -0.57 \\
\hline \multirow{3}{*}{$\begin{array}{l}\text { Growth/Inv } \\
\text { Opportunities }\end{array}$} & 5 Cat & 68.22 & 29.39 & 4.71 & -22.31 & -80.01 & & & & & & & & & & \\
\hline & 10Cat & 32.44 & 13.07 & 13.24 & 8.72 & 3.73 & -1.41 & -6.30 & -11.54 & -18.19 & -33.76 & & & & & \\
\hline & $15 \mathrm{Cat}$ & 25.90 & 9.77 & 11.07 & 9.22 & 7.05 & 4.97 & 2.89 & 0.72 & -1.40 & -3.57 & -5.85 & -8.66 & -11.51 & -16.32 & -24.28 \\
\hline \multirow{3}{*}{$\begin{array}{c}\text { Mkt to book } \\
\text { ratio }\end{array}$} & 5 Cat & 0.38 & 0.16 & 0.03 & -0.12 & -0.45 & & & & & & & & & & \\
\hline & 10Cat & -0.11 & -0.04 & -0.04 & -0.03 & -0.01 & 0.00 & 0.02 & 0.04 & 0.06 & 0.11 & & & & & \\
\hline & $15 \mathrm{Cat}$ & -0.08 & -0.03 & -0.03 & -0.03 & -0.02 & -0.01 & -0.01 & 0.00 & 0.00 & 0.01 & 0.02 & 0.03 & 0.03 & 0.05 & 0.07 \\
\hline
\end{tabular}


Table 10. Marginal effects of a standard deviation change in capital structure determinants when ranges are coded under the SNF criterion - Continued

\begin{tabular}{|c|c|c|c|c|c|c|c|c|c|c|c|c|c|c|c|c|}
\hline & & Range 1 & Range 2 & Range 3 & Range 4 & Range 5 & Range 6 & Range 7 & Range 8 & Range 9 & Range 10 & Range 11 & Range 12 & Range 13 & Range 14 & Range 15 \\
\hline \multirow{3}{*}{ Profitability } & 5 Cat & 1.83 & 0.79 & 0.13 & -0.60 & -2.14 & & & & & & & & & & \\
\hline & 10Cat & 1.03 & 0.42 & 0.42 & 0.28 & 0.12 & -0.04 & -0.20 & -0.37 & -0.58 & -1.08 & & & & & \\
\hline & $15 \mathrm{Cat}$ & 0.67 & 0.25 & 0.29 & 0.24 & 0.18 & 0.13 & 0.08 & 0.02 & -0.04 & -0.09 & -0.15 & -0.23 & -0.30 & -0.42 & -0.63 \\
\hline \multirow{3}{*}{$\begin{array}{l}\text { Internal } \\
\text { Reserves }\end{array}$} & 5 Cat & 1.20 & 0.52 & 0.08 & -0.39 & -1.41 & & & & & & & & & & \\
\hline & 10Cat & 0.39 & 0.16 & 0.16 & 0.11 & 0.05 & -0.02 & -0.08 & -0.14 & -0.22 & -0.41 & & & & & \\
\hline & 15Cat & 0.22 & 0.08 & 0.09 & 0.08 & 0.06 & 0.04 & 0.02 & 0.01 & -0.01 & -0.03 & -0.05 & -0.07 & -0.10 & -0.14 & -0.20 \\
\hline \multirow{3}{*}{ Z-Score } & 5 Cat & 1.92 & 0.83 & 0.13 & -0.63 & -2.25 & & & & & & & & & & \\
\hline & 10Cat & -2.19 & -0.88 & -0.89 & -0.59 & -0.25 & 0.10 & 0.42 & 0.78 & 1.23 & 2.28 & & & & & \\
\hline & 15Cat & -1.10 & -0.41 & -0.47 & -0.39 & -0.30 & -0.21 & -0.12 & -0.03 & 0.06 & 0.15 & 0.25 & 0.37 & 0.49 & 0.69 & 1.03 \\
\hline
\end{tabular}


Table 11. Marginal effects of the lagged dependent variable indicator on the model of 5 categories when ranges are coded under the ISW criterion: This table displays the marginal effects of the dummy variables that indicate in which range a firm was in the previous period for the model in which data was broken into 5 categories. The rows represent each of the categories included in the model. Category 4 was omitted due to multicollinearity. The columns indicate the range in which the firm was within in the previous period. These marginal effects were measured holding all the covariates at their mean values, changing the values of each dummy from 0 to 1 and registering the difference in the probability of being within each of the (5) ranges considered.

Range in the previous period

\begin{tabular}{cccccc}
\hline $\begin{array}{c}\text { Difference in the probability } \\
\text { of being in }\end{array}$ & Range 1 & Range 2 & Range 3 & Range 4 & Range 5 \\
\hline Range 1 & -5.13 & -16.60 & 6.41 & 12.63 & 2.69 \\
Range 2 & -8.98 & 4.43 & 3.97 & 0.56 & 0.02 \\
Range 3 & -4.54 & 3.20 & 1.22 & 0.11 & 0.00 \\
Range 5 & -0.90 & 0.69 & 0.19 & 0.01 & 0.00 \\
\hline
\end{tabular}


Table 12. Marginal effects of the lagged dependent variable indicator on the model of 10 categories when ranges are coded under the ISW criterion

This table displays the marginal effects of the dummy variables that indicate in which range a firm was in the previous period for the model in which data was broken into 10 categories. The rows represent each of the categories included in the model. Category 9 was omitted due to multicollinearity. The columns indicate the range in which the firm was within in the previous period. These marginal effects were measured holding all the covariates at their mean values, changing the values of each dummy from 0 to 1 and registering the difference in the probability of being within each of the (10) ranges considered.

Range in the previous period

\begin{tabular}{cccccccccccc}
\hline $\begin{array}{c}\text { Difference in the } \\
\text { probability of being } \\
\text { in }\end{array}$ & Range 1 & Range 2 & Range 3 & Range 4 & Range 5 & Range 6 & Range 7 & Range 8 & Range 9 & Range 10 \\
\hline Range 1 & -0.47 & -3.77 & -7.03 & -4.14 & 1.70 & 4.94 & 4.89 & 2.73 & 0.97 & 0.19 \\
Range 2 & -2.74 & -4.06 & 0.29 & 2.80 & 2.18 & 1.06 & 0.37 & 0.08 & 0.01 & 0.00 \\
Range 3 & -2.87 & -2.53 & 1.25 & 2.19 & 1.28 & 0.51 & 0.15 & 0.03 & 0.00 & 0.00 \\
Range 4 & -2.50 & -1.39 & 1.31 & 1.50 & 0.74 & 0.26 & 0.07 & 0.01 & 0.00 & 0.00 \\
Range 5 & -1.89 & -0.70 & 1.04 & 0.96 & 0.42 & 0.13 & 0.03 & 0.01 & 0.00 & 0.00 \\
Range 6 & -1.42 & -0.40 & 0.79 & 0.66 & 0.27 & 0.08 & 0.02 & 0.00 & 0.00 & 0.00 \\
Range 7 & -1.05 & -0.23 & 0.58 & 0.45 & 0.18 & 0.05 & 0.01 & 0.00 & 0.00 & 0.00 \\
Range 8 & -0.68 & -0.13 & 0.38 & 0.28 & 0.11 & 0.03 & 0.01 & 0.00 & 0.00 & 0.00 \\
Range 10 & -0.30 & -0.05 & 0.16 & 0.12 & 0.05 & 0.01 & 0.00 & 0.00 & 0.00 & 0.00 \\
\hline
\end{tabular}


Table 13. Marginal effects of the lagged dependent variable indicator on the model of $\mathbf{1 5}$ categories when

ranges are coded under the ISW criterion: This table displays the marginal effects of the dummy variables that indicate in which range a firm was in the previous period for the model in which data was broken into 15 categories. The rows represent each of the categories included in the model. Category 14 was omitted due to multicollinearity. The columns indicate the range in which the firm was within in the previous period. These marginal effects were measured holding all the covariates at their mean values, changing the values of each dummy from 0 to 1 and registering the difference in the probability of being within each of the (15) ranges considered.

\begin{tabular}{|c|c|c|c|c|c|c|c|c|c|c|c|c|c|c|c|}
\hline \multirow{2}{*}{$\begin{array}{l}\text { Difference in } \\
\text { the } \\
\text { probability of } \\
\text { being in }\end{array}$} & \multicolumn{15}{|c|}{ Range in the previous period } \\
\hline & Range 1 & Range 2 & Range 3 & Range 4 & Range 5 & Range 6 & Range 7 & Range 8 & Range 9 & Range 10 & Range 11 & Range 12 & Range 13 & Range 14 & Range 15 \\
\hline Range 1 & -0.23 & -1.52 & -3.48 & -4.32 & -2.66 & -0.28 & 1.79 & 2.74 & 2.84 & 2.29 & 1.62 & 0.73 & 0.35 & 0.12 & 0.02 \\
\hline Range 2 & -1.33 & -2.56 & -1.56 & 0.33 & 1.35 & 1.48 & 1.07 & 0.64 & 0.34 & 0.16 & 0.06 & 0.02 & 0.00 & 0.00 & 0.00 \\
\hline Range 3 & -1.46 & -2.20 & -0.89 & 0.70 & 1.25 & 1.14 & 0.73 & 0.40 & 0.20 & 0.08 & 0.03 & 0.01 & 0.00 & 0.00 & 0.00 \\
\hline Range 4 & -1.45 & -1.87 & -0.53 & 0.79 & 1.10 & 0.91 & 0.55 & 0.28 & 0.13 & 0.05 & 0.02 & 0.00 & 0.00 & 0.00 & 0.00 \\
\hline Range 5 & -1.29 & -1.40 & -0.20 & 0.74 & 0.85 & 0.65 & 0.36 & 0.18 & 0.08 & 0.03 & 0.01 & 0.00 & 0.00 & 0.00 & 0.00 \\
\hline Range 6 & -1.17 & -1.15 & -0.08 & 0.68 & 0.71 & 0.52 & 0.28 & 0.13 & 0.06 & 0.02 & 0.01 & 0.00 & 0.00 & 0.00 & 0.00 \\
\hline Range 7 & -0.94 & -0.82 & 0.01 & 0.53 & 0.52 & 0.36 & 0.19 & 0.09 & 0.04 & 0.01 & 0.00 & 0.00 & 0.00 & 0.00 & 0.00 \\
\hline Range 8 & -0.80 & -0.65 & 0.05 & 0.45 & 0.42 & 0.28 & 0.15 & 0.07 & 0.03 & 0.01 & 0.00 & 0.00 & 0.00 & 0.00 & 0.00 \\
\hline Range 9 & -0.65 & -0.51 & 0.05 & 0.37 & 0.33 & 0.22 & 0.11 & 0.05 & 0.02 & 0.01 & 0.00 & 0.00 & 0.00 & 0.00 & 0.00 \\
\hline Range 10 & -0.54 & -0.40 & 0.06 & 0.30 & 0.26 & 0.17 & 0.09 & 0.04 & 0.02 & 0.01 & 0.00 & 0.00 & 0.00 & 0.00 & 0.00 \\
\hline Range 11 & -0.42 & -0.31 & 0.05 & 0.24 & 0.20 & 0.13 & 0.07 & 0.03 & 0.01 & 0.00 & 0.00 & 0.00 & 0.00 & 0.00 & 0.00 \\
\hline Range 12 & -0.28 & -0.20 & 0.04 & 0.16 & 0.13 & 0.09 & 0.04 & 0.02 & 0.01 & 0.00 & 0.00 & 0.00 & 0.00 & 0.00 & 0.00 \\
\hline Range 13 & -0.23 & -0.16 & 0.03 & 0.13 & 0.11 & 0.07 & 0.03 & 0.01 & 0.01 & 0.00 & 0.00 & 0.00 & 0.00 & 0.00 & 0.00 \\
\hline Range 15 & -0.13 & -0.09 & 0.02 & 0.07 & 0.06 & 0.04 & 0.02 & 0.01 & 0.00 & 0.00 & 0.00 & 0.00 & 0.00 & 0.00 & 0.00 \\
\hline
\end{tabular}


Table 14. Marginal effects of the lagged dependent variable indicator on the model of 5 categories when ranges are coded under the SNF criterion: This table displays the marginal effects of the dummy variables that indicate in which range a firm was in the previous period for the model in which data was broken into 5 categories. The rows represent each of the categories included in the model. Category 4 was omitted due to multicollinearity. The columns indicate the range in which the firm was within in the previous period. These marginal effects were measured holding all the covariates at their mean values, changing the values of each dummy from 0 to 1 and registering the difference in the probability of being within each of the (5) ranges considered.

\begin{tabular}{cccccc}
\cline { 2 - 6 } & \multicolumn{5}{c}{ Range in the previous period } \\
\hline $\begin{array}{c}\text { Difference in the } \\
\text { probability of } \\
\text { being in }\end{array}$ & Range 1 & Range 2 & Range 3 & Range 4 & Range 5 \\
\hline Range 1 & -0.28 & -3.46 & -4.19 & 3.97 & 3.95 \\
Range 2 & -0.49 & -4.35 & -3.04 & 4.94 & 2.94 \\
Range 3 & -0.72 & -4.93 & -1.93 & 5.28 & 2.29 \\
Range 5 & -1.59 & -5.65 & 1.11 & 5.01 & 1.12 \\
\hline
\end{tabular}


Table 15. Marginal effects of the lagged dependent variable indicator on the model of 10 categories when ranges are coded under the SNF criterion: This table displays the marginal effects of the dummy variables that indicate in which range a firm was in the previous period for the model in which data was broken into 10 categories. The rows represent each of the categories included in the model. Category 9 was omitted due to multicollinearity. The columns indicate the range in which the firm was within in the previous period. These marginal effects were measured holding all the covariates at their mean values, changing the values of each dummy from 0 to 1 and registering the difference in the probability of being within each of the (10) ranges considered.

Range in the previous period

Difference in the

probability of being Range 1 Range 2 Range 3 Range 4 Range 5 Range 6 Range 7 Range 8 Range 9 Range 10

\begin{tabular}{|c|c|c|c|c|c|c|c|c|c|c|}
\hline Range 1 & -0.02 & -0.18 & -0.79 & -1.49 & -1.60 & -0.65 & 0.84 & 1.91 & 1.59 & 0.40 \\
\hline Range 2 & -0.03 & -0.22 & -0.78 & -1.16 & -0.90 & 0.01 & 0.92 & 1.24 & 0.78 & 0.15 \\
\hline Range 3 & -0.04 & -0.26 & -0.94 & -1.43 & -1.15 & -0.04 & 1.11 & 1.56 & 1.00 & 0.19 \\
\hline Range 4 & -0.05 & -0.29 & -1.01 & -1.45 & -1.08 & 0.07 & 1.17 & 1.53 & 0.93 & 0.17 \\
\hline Range 5 & -0.05 & -0.32 & -1.06 & -1.47 & -1.01 & 0.17 & 1.22 & 1.50 & 0.87 & 0.15 \\
\hline Range 6 & -0.06 & -0.35 & -1.12 & -1.48 & -0.94 & 0.26 & 1.27 & 1.46 & 0.81 & 0.14 \\
\hline Range 7 & -0.07 & -0.38 & -1.17 & -1.48 & -0.87 & 0.36 & 1.30 & 1.43 & 0.76 & 0.12 \\
\hline Range 8 & -0.08 & -0.42 & -1.24 & -1.48 & -0.77 & 0.47 & 1.34 & 1.37 & 0.69 & 0.10 \\
\hline Range 10 & -0.12 & -0.55 & -1.41 & -1.41 & -0.46 & 0.76 & 1.39 & 1.20 & 0.53 & 0.07 \\
\hline
\end{tabular}


Table 16. Marginal effects of the lagged dependent variable indicator on the model of 15 categories when

ranges are coded under the SNF criterion: This table displays the marginal effects of the dummy variables that indicate in which range a firm was in the previous period for the model in which data was broken into 15 categories. The rows represent each of the categories included in the model. Category 14 was omitted due to multicollinearity. The columns indicate the range in which the firm was within in the previous period. These marginal effects were measured holding all the covariates at their mean values, changing the values of each dummy from 0 to 1 and registering the difference in the probability of being within each of the (15) ranges considered.

\begin{tabular}{|c|c|c|c|c|c|c|c|c|c|c|c|c|c|c|c|}
\hline $\begin{array}{l}\text { Difference } \\
\text { in the } \\
\text { probability } \\
\text { of being in }\end{array}$ & Range 1 & Range 2 & Range 3 & Range 4 & Range 5 & Range 6 & Range 7 & Range 8 & Range 9 & Range 10 & Range 11 & Range 12 & Range 13 & Range 14 & Range 15 \\
\hline Range 1 & -0.01 & -0.03 & -0.15 & -0.38 & -0.63 & -0.79 & -0.77 & -0.49 & -0.06 & 0.41 & 0.77 & 0.92 & 0.74 & 0.39 & 0.07 \\
\hline Range 2 & -0.01 & -0.03 & -0.15 & -0.32 & -0.47 & -0.51 & -0.41 & -0.16 & 0.13 & 0.38 & 0.51 & 0.51 & 0.35 & 0.16 & 0.02 \\
\hline Range 3 & -0.01 & -0.04 & -0.17 & -0.38 & -0.57 & -0.64 & -0.53 & -0.24 & 0.12 & 0.45 & 0.64 & 0.66 & 0.47 & 0.22 & 0.03 \\
\hline Range 4 & -0.01 & -0.04 & -0.18 & -0.40 & -0.60 & -0.66 & -0.54 & -0.23 & 0.14 & 0.47 & 0.66 & 0.67 & 0.47 & 0.22 & 0.03 \\
\hline Range 5 & -0.01 & -0.04 & -0.19 & -0.42 & -0.60 & -0.66 & -0.53 & -0.21 & 0.16 & 0.49 & 0.66 & 0.66 & 0.45 & 0.21 & 0.03 \\
\hline Range 6 & -0.01 & -0.05 & -0.20 & -0.43 & -0.62 & -0.66 & -0.51 & -0.19 & 0.19 & 0.50 & 0.66 & 0.65 & 0.44 & 0.20 & 0.03 \\
\hline Range 7 & -0.01 & -0.05 & -0.21 & -0.44 & -0.62 & -0.66 & -0.50 & -0.17 & 0.21 & 0.51 & 0.66 & 0.64 & 0.43 & 0.19 & 0.02 \\
\hline Range 8 & -0.01 & -0.05 & -0.22 & -0.45 & -0.63 & -0.66 & -0.49 & -0.15 & 0.22 & 0.52 & 0.66 & 0.63 & 0.42 & 0.18 & 0.02 \\
\hline Range 9 & -0.01 & -0.06 & -0.23 & -0.47 & -0.64 & -0.66 & -0.47 & -0.13 & 0.25 & 0.54 & 0.66 & 0.62 & 0.40 & 0.17 & 0.02 \\
\hline Range 10 & -0.01 & -0.06 & -0.23 & -0.48 & -0.65 & -0.65 & -0.46 & -0.11 & 0.26 & 0.55 & 0.66 & 0.61 & 0.39 & 0.16 & 0.02 \\
\hline Range 11 & -0.01 & -0.06 & -0.24 & -0.49 & -0.66 & -0.65 & -0.44 & -0.09 & 0.28 & 0.56 & 0.66 & 0.60 & 0.38 & 0.16 & 0.02 \\
\hline Range 12 & -0.02 & -0.07 & -0.25 & -0.50 & -0.66 & -0.65 & -0.43 & -0.06 & 0.30 & 0.57 & 0.66 & 0.59 & 0.36 & 0.15 & 0.02 \\
\hline Range 13 & -0.02 & -0.07 & -0.27 & -0.52 & -0.67 & -0.64 & -0.41 & -0.04 & 0.32 & 0.58 & 0.65 & 0.57 & 0.35 & 0.14 & 0.02 \\
\hline Range 15 & -0.02 & -0.09 & -0.31 & -0.57 & -0.69 & -0.60 & -0.33 & 0.05 & 0.39 & 0.60 & 0.63 & 0.52 & 0.30 & 0.11 & 0.01 \\
\hline
\end{tabular}


Table 17. In-sample and out-of-sample predictability: The table displays the proportion, relative to the total of observations, of times in which the estimated dynamic ordered probit correctly "predicted" the range in which a firm is. We perform this analysis for the observations used in the estimation of the model (in-sample) and the ones not used (out-of-sample). The last line of the table represents the difference in percentage points between the proportion of insample and out-of-sample right predicted ranges.

\begin{tabular}{lccccccc}
\hline & \multicolumn{3}{c}{ ISW } & & \multicolumn{3}{c}{ SNF } \\
\cline { 2 - 4 } \cline { 6 - 8 } & 5 & 10 & 15 & & 5 & 10 & 15 \\
\hline In-sample & 71.72 & 54.29 & 45.11 & & 60.75 & 30.8 & 21.71 \\
Out-of-sample & 59.78 & 42.96 & 4.87 & & 51.48 & 30.34 & 13.38 \\
\hline $\begin{array}{l}\text { (In-Sample) - } \\
\text { (Out-of-sample) }\end{array}$ & -11.94 & -11.33 & -40.24 & & -9.27 & -0.46 & -8.33 \\
\hline
\end{tabular}


Table 18. Inertia: The table presents Fama-MacBeth (1973) estimates of Welch (2004) inertia hypothesis for two subsamples: firms whose level of leverage is within the calculated target range and the ones that are out of it. The estimated equation is

$$
\frac{D_{t+1}}{D_{t+1}+E_{t+1}}=\alpha_{0}+\alpha_{1} \cdot \frac{D_{t}}{D_{t}+E_{t}}+\alpha_{2} \cdot \frac{D_{t}}{D_{t}+E_{t} \cdot\left(1+r_{t, t+1}\right)}+\delta_{t}+\alpha_{3}\left(\delta_{t} \cdot \frac{D_{t}}{D_{t}+E_{t}}\right)+\alpha_{4}\left(\delta_{t} \cdot \frac{D_{t}}{D_{t}+E_{t} \cdot\left(1+r_{t, t+1}\right)}\right)+\varepsilon_{t, t+1}
$$

Where $D_{t}$ is the firm's debt value, $E_{t}$ is the firm's equity value, $r_{t, t+1}=\frac{E_{t+1}-E_{t}}{E_{t}}, \delta_{t}$ is a dummy variable that equals 1 when the level of leverage of a firm is within the optimal calculated range in period $t$, and 0 otherwise, $\varepsilon_{t, t+1}$ is a random error. The sample consists of annual COMPUSTAT data from 1991 to 2006 , excluding financial (SIC's 6000-6999) and regulated (SICs 4900-4999) firms. Under inertia hypothesis $\alpha_{1}=0$ and $\alpha_{2}=1$. The difference between for $\alpha_{2}$ for the observations within the target calculated range and the ones out of it is significant if $\alpha_{4}$ is significant. The standard deviations are presented in parentheses below the corresponding estimate. Statistical significance at $1 \%$ and $5 \%$ levels is indicated by one and asterisks, respectively.

\begin{tabular}{|c|c|c|c|c|c|c|}
\hline & \multicolumn{2}{|c|}{ Cat 5} & \multicolumn{2}{|c|}{ Cat 10} & \multicolumn{2}{|c|}{ Cat 15} \\
\hline & ISW & $\mathrm{SNF}$ & ISW & SNF & ISW & $\mathrm{SNF}$ \\
\hline \multirow[t]{2}{*}{$\alpha_{0}$} & $0.02^{*}$ & $0.03^{*}$ & $0.02^{*}$ & $0.02^{*}$ & $0.02^{*}$ & $0.02^{*}$ \\
\hline & $(0.00)$ & $(0.00)$ & $(0.00)$ & $(0.00)$ & $(0.00)$ & $(0.00)$ \\
\hline \multirow[t]{2}{*}{$\alpha_{1}$} & 0.01 & -0.01 & 0.01 & 0.01 & 0.01 & 0.01 \\
\hline & $(0.02)$ & $(0.03)$ & $(0.02)$ & $(0.02)$ & $(0.02)$ & $(0.02)$ \\
\hline \multirow[t]{2}{*}{$\alpha_{2}$} & $0.89^{*}$ & $0.88^{*}$ & $0.89^{*}$ & $0.87^{*}$ & $0.88^{*}$ & $0.88^{*}$ \\
\hline & $(0.03)$ & $(0.03)$ & $(0.02)$ & $(0.02)$ & $(0.02)$ & $(0.02)$ \\
\hline \multirow[t]{2}{*}{$\delta$} & 0.00 & $-0.01^{*}$ & $-0.00^{* *}$ & -0.01 & $0.00^{*}$ & 0.00 \\
\hline & $(0.00)$ & $(0.00)$ & $(0.00)$ & $(0.00)$ & $(0.00)$ & $(0.00)$ \\
\hline \multirow[t]{2}{*}{$\alpha_{3}$} & 0.02 & 0.03 & 0.00 & -0.01 & 0.00 & -0.03 \\
\hline & $(0.04)$ & $(0.04)$ & $(0.04)$ & $(0.04)$ & $(0.04)$ & $(0.03)$ \\
\hline \multirow[t]{2}{*}{$\alpha_{4}$} & -0.01 & 0.02 & 0.01 & $0.06^{* *}$ & 0.03 & $0.07^{*}$ \\
\hline & $(0.04)$ & $(0.04)$ & $(0.05)$ & $(0.03)$ & $(0.05)$ & $(0.03)$ \\
\hline $\mathrm{R}^{2}$ & 0.85 & 0.85 & 0.85 & 0.85 & 0.85 & 0.85 \\
\hline
\end{tabular}

